(C) 2018 Universidad Nacional Autónoma de México, Facultad de Estudios Superiores Zaragoza.

Este es un artículo Open Access bajo la licencia CC BY-NC-ND (http://creativecommons.org/licenses/by-nc-nd/4.0/).

TIP Revista Especializada en Ciencias Químico-Biológicas, 21(Supl. 2): 51-68, 2018.

DOI: $10.22201 /$ fesz.23958723e.2018.0.155

\title{
DescontaminaCión de ARSÉNICO, CADMIO Y PLOMO EN AGUA POR BIOSORCIÓN CON Saccharomyces cerevisiae
}

\author{
Silvia Carolina Moreno-Rivas ${ }^{1}$ y Gabriela Ramos-Clamont Montfort ${ }^{1 *}$ \\ ${ }^{1}$ Centro de Investigación en Alimentación y Desarrollo, A. C. Carretera a La Victoria \\ km 0.6, Hermosillo, 83304 Sonora, México.*E-mail: gramos@ciad.mx
}

\begin{abstract}
ResUmen
La contaminación del agua con metales pesados es un problema potencial de salud pública, debido a su toxicidad. Los métodos tradicionales de descontaminación se enfocan principalmente a tratar efluentes industriales con altas concentraciones de metales pesados, pero con desventajas por los altos costos, grandes espacios de operación y en ocasiones, empleo o generación de otras sustancias tóxicas. Los metales pesados con mayor toxicidad presentes en el agua son arsénico, cadmio y plomo, cuya exposición crónica puede dañar diversos órganos y promover el desarrollo de cáncer. La eliminación de estos metales del agua de consumo con menores concentraciones que aún representen un riesgo a la salud, puede llevarse a cabo por el fenómeno de biosorción. Los materiales biosorbentes son molecularmente, diversos, económicos y pueden ser desde biopolímeros hasta biomasa microbiana. Se conoce que algunas cepas de levaduras han mostrado gran capacidad de remoción de metales pesados en soluciones acuosas, destacando las del género Saccharomyces, particularmente Saccharomyces cerevisiae. La biosorción con levaduras es una alternativa prometedora para la eliminación de bajas concentraciones de $\mathrm{As}^{3+}, \mathrm{As}^{5+}, \mathrm{Cd}^{2+} \mathrm{y} \mathrm{Pb}^{2+}$ en agua de consumo. Sin embargo, es necesario seguir estudiando las condiciones para su aplicación a gran escala, así como otras posibilidades que permitan su optimización.
\end{abstract}

Palabras Clave: descontaminación, metales pesados, biosorción, biomasa, levadura.

\section{Decontamination of arsenic, cadmium and lead in groundwater by biosorption with Saccharomyces cerevisiae}

\begin{abstract}
Heavy metals pollution in water represents a potential public health problem due to its toxicity. Traditional methods of decontamination are mainly focused on the treatment of industrial effluents with high concentrations of heavy metals. In addition, these methods have some disadvantages in their application, such as high costs, large operating spaces and sometimes, employment or generation of other toxic substances. Heavy metals with higher toxicity in water are arsenic, cadmium and lead. Chronic exposure to these heavy metals may damage various organs and promote the development of cancer in humans. The elimination of these heavy metals in drinking water, with lower concentrations that still represent a health risk, can be carried out by the biosorption phenomenon. Biosorbent materials are diverse and economical, ranging from biopolymers to microbial biomass. In this respect, some strains of yeast have great capacity for heavy metals removal in aqueous solutions, especially those of the genus Saccharomyces, particularly Saccharomyces cerevisiae. Biosorption by yeasts is a promising alternative for removing low concentrations of $\mathrm{As}^{3+}, \mathrm{As}^{5+}, \mathrm{Cd}^{2+}$ and $\mathrm{Pb}^{2+}$ in drinking water. However, it is necessary to continue studying the conditions for its large-scale application, as well as other possibilities that allow its optimization.
\end{abstract}

Key Words: decontamination, heavy metals, biosorption, biomass, yeast.

Nota: Artículo recibido el 24 de enero del 2018 y aceptado el 01 de octubre del 2018. 


\section{INTRODUCCIÓN}

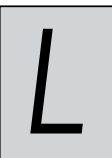

a clasificación química inicial para definir al grupo de metales pesados estaba basada principalmente en el agrupamiento de elementos con similitudes entre sus propiedades fisicoquímicas (Rajendran, Muthukrishnan \& Gunasekaran, 2003). Ésta incluía a los metales de transición y a algunos semimetales, como el arsénico (Duffus, 2002). Sin embargo, en materia de química ambiental, la clasificación se basa principalmente, en términos de toxicidad (Duffus, 2002). En este sentido y de acuerdo a la lista de contaminantes prioritarios de la Agencia de Protección Ambiental de los Estados Unidos (USEPA, por sus siglas en inglés), los metales pesados incluyen a elementos como: arsénico $(\mathrm{As})$, cromo $(\mathrm{Cr})$, cobalto $(\mathrm{Co})$, níquel $(\mathrm{Ni})$, cobre $(\mathrm{Cu})$, zinc $(\mathrm{Zn})$, plata $(\mathrm{Ag})$, cadmio $(\mathrm{Cd})$, mercurio $(\mathrm{Hg})$, titanio $(\mathrm{Ti})$, selenio (Se) y plomo (Pb) (INECC, 2009).

En particular, $\mathrm{As}, \mathrm{Cd} \mathrm{y} \mathrm{Pb}$, son altamente tóxicos y pueden contaminar las fuentes de agua para consumo. La contaminación proviene principalmente de actividades antropogénicas. En el caso de As y Cd, también pueden emanar de depósitos terrestres naturales (Armah, Quansah \& Luginaah, 2014). Entre las actividades antropogénicas que más contaminan al agua con metales pesados destacan la minería y la metalurgia, producción de cromados, pinturas y escurrimientos a partir de chatarra electrónica. Algunos plaguicidas arsenicales muy persistentes (actualmente prohibidos), también contaminan suelo y agua con estos metales pesados (Armah, Quansah \& Luginaah, 2014; Arreguín Cortés, Chávez Guillén, Soto Navarro \& Smedley, 2010). En la Figura 1 se presentan las diferentes fuentes de contaminación. Puede observarse que algunas actividades, como la minería y la metalurgia, pueden contaminar el agua con los tres metales, siendo actualmente, uno de los principales focos de atención (Chowdhury, Mazumder, Al-Attas \& Husain, 2016). Por tanto, estas empresas deben realizar un tratamiento a las aguas industriales y extremar las precauciones para prevenir derrames en los jales mineros. Estas acciones evitarán en gran medida la contaminación de los cuerpos de agua y la entrada de metales pesados a la cadena alimenticia (Armah, Quansah \& Luginaah, 2014; Arreguín Cortés, Chávez Guillén, Soto Navarro \& Smedley, 2010; Ferreira, Koricheva, Duarte, Niyogi \& Guérold, 2016).

Para evitar los daños causados por estos metales pesados, es primordial establecer medidas preventivas, como el control de fuentes de emisión al ambiente y el manejo de residuos y tratamiento de aguas residuales (Central Pollution Control Board, 2007). Para el agua destinada a consumo, es imperante

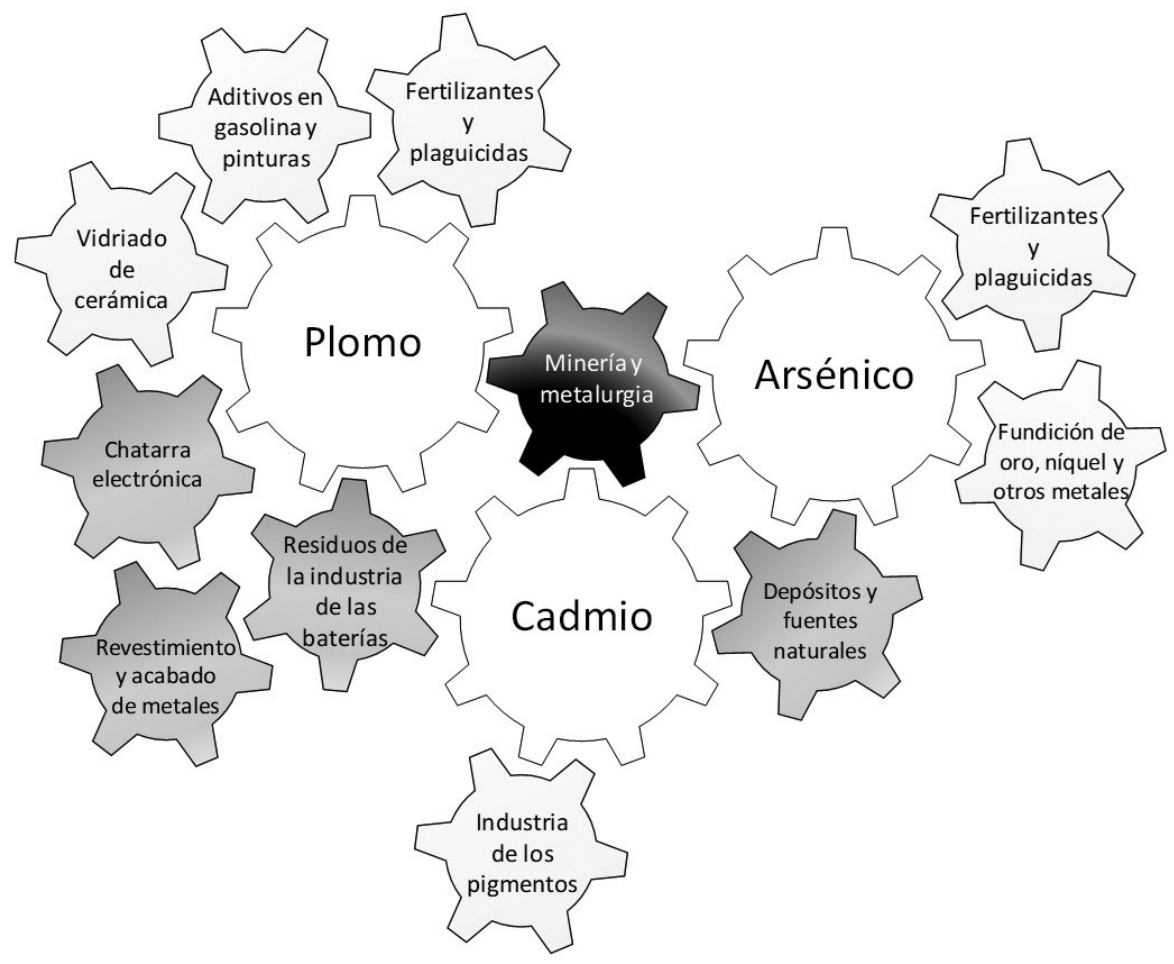

Figura 1. Fuentes de contaminación de cuerpos de agua con arsénico (As), cadmio (Cd) y plomo (Pb). Los colores de las casillas que representan a las fuentes de contaminación indican que ésta es producida por uno (blanco), por dos (gris) o por los tres metales pesados (negro). Fuente: Elaboración propia. 
controlar los derrames y escurrimientos industriales y regular el uso de aleaciones y galvanizados en tuberías, grifos y filtros (WHO, 2011). Además, es necesario el cumplimiento de las legislaciones con respecto a los límites máximos permitidos y la observancia de las normas por parte de las autoridades competentes (Central Pollution Control Board, 2007). Por otro lado, cuando la contaminación por metales pesados ya se ha dado, deberán tomarse acciones correctivas para eliminarla o disminuirla, por debajo de los valores permisibles (WHO, 2011).

Para tratar aguas de efluentes industriales que contengan concentraciones de metales pesados $>100 \mathrm{mg} / \mathrm{L}$, se usan métodos que implican operaciones unitarias como precipitación, coagulación/floculación, filtración por membranas e intercambio iónico (Barakat, 2011; Lin \& Harichund, 2011). Sin embargo, cuando se trata de agua de consumo, en la que las concentraciones de metales van de $1-100 \mathrm{mg} / \mathrm{L}$ o menores, los métodos mencionados representan altos costos operativos, grandes espacios de operación y en ocasiones, el empleo o generación de otras sustancias tóxicas (Rao, Mohapatra, Anand \& Venkateswarlu, 2010; Wang \& Chen, 2006).

El uso de métodos como la biosorción, donde se emplean agentes de origen biológico, representa una alternativa viable para la descontaminación del agua de consumo con metales. Es importante destacar que, para el humano y otros organismos vivos, concentraciones muy bajas de metales pesados (del orden de los $\mu \mathrm{g} / \mathrm{L}$ ), siguen constituyendo un importante riesgo a la salud. Por lo anterior, el objetivo de esta revisión, es contribuir con información sistematizada y brindar un panorama general, acerca del fenómeno de biosorción y el uso de biosorbentes potenciales, en particular, la biomasa de la levadura S. cerevisiae Meyen ex E.C. Hansen (Ascomycota: Saccharomycotina), para descontaminar el agua para consumo, de metales pesados, resaltando además el riesgo que implica en la salud humana, la exposición a estos contaminantes.

\section{IMPACTO DE ARSÉNICO, CADMIO Y PLOMO EN LA SALUD HUMANA}

La presencia de metales pesados en el agua que consumimos, representa un riesgo a la salud pública. Dentro de este tipo de metales, destacan $\mathrm{As}, \mathrm{Cd}$ y $\mathrm{Pb}$ por su alta toxicidad. $\mathrm{La}$ Agencia Internacional de Investigación en Cáncer (IARC, por sus siglas en inglés), clasifica al As y al Cd en el grupo 1, que incluye a los promotores de cáncer en humanos, conocidos hasta el momento (IARC, 2016). El Pb está catalogado en el grupo 2B, como posible carcinógeno (IARC, 2016).

Los efectos tóxicos de los metales pesados en humanos dependen de la edad, género y estados tanto de salud, como nutricional del individuo (Jaishankar, Tseten, Anbalagan, Mathew \& Beeregowda, 2014). Generalmente los infantes, adultos mayores y personas inmunocomprometidas son más susceptibles al daño (Tchounwou, Yedjou, Patlolla \& Sutton,
2012). La forma química (especie, valencia, inorgánico vs. orgánico), dosis, ruta de entrada, tiempo de exposición (aguda vs. crónica) y capacidad del organismo para metabolizar al metal en compuestos menos tóxicos, son determinantes del tipo y extensión del daño (Jaishankar, Tseten, Anbalagan, Mathew \& Beeregowda, 2014). Algunos aspectos importantes, relacionados con la toxicidad de $\mathrm{As}, \mathrm{Cd}$ y $\mathrm{Pb}$, se resumen en la Tabla I.

En el caso de agua de consumo contaminada con arsénico, es importante considerar la exposición prolongada (crónica o silenciosa) en la que, las principales especies presentes, arsenito $\left(\mathrm{As}^{3+}\right)$ y arsenato $\left(\mathrm{As}^{5+}\right)$, causan alteraciones en la piel y el sistema nervioso, así como cáncer en pulmón, hígado, riñón y vejiga (Jaishankar, Tseten, Anbalagan, Mathew \& Beeregowda, 2014). También, complicaciones cardiovasculares y diabetes mellitus en personas propensas y otros tipos de cáncer (Shankar, Shanker \& Shikha, 2014). Por su parte, la ingestión crónica de Cd, en todas sus formas químicas, causa fallo renal, osteoporosis, anemia, cáncer en pulmón, riñón, seno y próstata (Hartwig, 2013). En el caso del $\mathrm{Pb}$ se observa neuro y nefrotoxicidad, alteraciones psicomotoras, hipertensión, alteraciones cardiovasculares y del sistema hematológico, además de posible desarrollo de cáncer en pulmón, estómago, cerebro y riñón (Bandyopadhyay et al., 2014; IARC, 2016).

El efecto de una exposición continua a metales pesados en la salud, se encuentra muy relacionado con la dosis de exposición (Jaishankar, Tseten, Anbalagan, Mathew \& Beeregowda, 2014). Por ejemplo, en nativos americanos, García-Esquinas et al. (2013), encontraron una asociación directa entre las

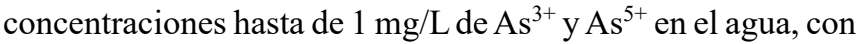
la aparición de cáncer en pulmón, páncreas y próstata. En un estudio en mujeres del norte de México (Coahuila, Chihuahua, Durango, Nuevo León y Sonora), enfermas de cáncer de mama, López-Carrillo et al. (2014) encontraron que el $60 \%$ de ellas estuvieron expuestas a niveles de $\mathrm{As}^{3+} \mathrm{yAs}^{5+}$ en agua, superiores a $10 \mu \mathrm{g} / \mathrm{L}$, mientras que el $34 \%$ de ellas, a concentraciones superiores a $25 \mu \mathrm{g} / \mathrm{L}$. Basándose en los estudios epidemiológicos y modelos existentes, algunas agencias canadienses proponen que la concentración de arsénico en agua que no produce daños al organismo es de $0.3 \mu \mathrm{g} / \mathrm{L}$ (FPTCDW, 2006).

Existe evidencia científica de que el estrés oxidativo es el principal desencadenante de la toxicidad de los metales pesados (Jomova et al., 2011; Tchounwou, Yedjou, Patlolla \& Sutton, 2012). Éstos, inducen la generación de especies reactivas de oxígeno (por ejemplo, ${ }^{\circ} \mathrm{O}_{2}^{-}, \mathrm{H}_{2} \mathrm{O}_{2}, \mathrm{RO} \cdot$, ROO') que producen daños a proteínas, $\mathrm{ADN}$, y lípidos, localizados en diferentes organelos celulares (Tchounwou, Yedjou, Patlolla $\&$ Sutton, 2012). Por ejemplo, las especies de $\mathrm{Cd}$, el $\mathrm{As}^{3+}$ y el ácido monometil arsónico $\left(\mathrm{CH}_{3} \mathrm{AsO}(\mathrm{OH})_{2}\right)$, producen daño en la conformación del ADN disminuyendo su capacidad de reparación, alterando el ciclo celular, incluido el proceso de 


\begin{tabular}{|c|c|c|c|}
\hline Característica & Arsénico & Cadmio & Plomo \\
\hline $\begin{array}{l}\text { Formas químicas } \\
\text { más tóxicas }\end{array}$ & $\begin{array}{l}\text { Arsenato y arsenito son las especies } \\
\text { más frecuentes en agua; bastante } \\
\text { tóxicas; al metilarse en el organismo } \\
\text { disminuye su toxicidad }\end{array}$ & $\begin{array}{c}\text { Todas las especies son muy } \\
\text { tóxicas. El } \mathrm{Cd}^{2+} \text { es soluble } \\
\text { en agua en un amplio rango } \\
\text { de pH. En pH alcalino } \\
\text { persisten los hidróxidos }\end{array}$ & $\begin{array}{l}\text { Las especies de } \mathrm{Pb} \text { son generalmente } \\
\text { tóxicas. En agua se encuentra } \\
\text { disuelto en forma de sulfatos e } \\
\text { hidróxidos. A pH ácido se encuentra } \\
\text { como catión divalente }\end{array}$ \\
\hline $\begin{array}{c}\text { Principales rutas } \\
\text { de entrada }\end{array}$ & Ingestión & Ingestión e inhalación & Ingestión e inhalación \\
\hline $\begin{array}{c}\text { Absorción } \\
\text { después de } \\
\text { ingestión }(\%) \\
\end{array}$ & $>80$ & 5 & 10 \\
\hline $\begin{array}{l}\text { Cinética y } \\
\text { metabolismo }\end{array}$ & $\begin{array}{c}\text { Se distribuye en tejidos blancos; se } \\
\text { metaboliza mediante reacciones de } \\
\text { oxidación-reducción, seguidas de } \\
\text { metilación }\end{array}$ & $\begin{array}{l}\text { Se distribuye en hígado y } \\
\text { riñón, formando complejos } \\
\text { con metaloproteínas }\end{array}$ & $\begin{array}{c}\text { Se une a proteínas de eritrocitos y } \\
\text { de tejidos suaves y huesos (donde se } \\
\text { acumula) }\end{array}$ \\
\hline $\begin{array}{l}\text { Vida media } \\
\text { biológica }\end{array}$ & $\begin{array}{c}\text { Especies inorgánicas se excretan } \\
\text { después de } 3 \text { a } 5 \text { días, las metiladas } \\
\text { más rápidamente }\end{array}$ & $>10$ años & $\begin{array}{l}\text { En sangre } 20 \text { a } 40 \text { días } \\
\text { En tejidos y huesos } \\
10 \text { a } 30 \text { años }\end{array}$ \\
\hline $\begin{array}{l}\text { Principal vía de } \\
\text { excreción }\end{array}$ & Orina & Orina & Orina \\
\hline $\begin{array}{c}\text { Principales } \\
\text { órganos de } \\
\text { acumulación } \\
\end{array}$ & Tejidos queratinosos & Hígado y riñón & Huesos, riñones e hígado \\
\hline Toxicidad aguda & $\begin{array}{c}\text { Dependiendo de la concentración: } \\
\text { Dolor abdominal, vómito, diarrea, } \\
\text { disminución del volumen sanguíneo; } \\
\text { neuropatía periférica; falla } \\
\text { multiorgánica, muerte }\end{array}$ & $\begin{array}{l}\text { Pérdida de fluidos, } \\
\text { shock, edema pulmonar, } \\
\text { hipotensión, oliguria, falla } \\
\text { multiorgánica; muerte }\end{array}$ & $\begin{array}{l}\text { Nefritis, hipertensión, encefalopatía; } \\
\text { dolor abdominal, vómito, } \\
\text { convulsiones, coma; daño hepático } \\
\text { y renal }\end{array}$ \\
\hline $\begin{array}{l}\text { Toxicidad } \\
\text { crónica }\end{array}$ & $\begin{array}{c}\text { Desarrollo de lesiones en la piel; } \\
\text { neurotoxicidad, ataxia; anemia; } \\
\text { leucopenia; cáncer en pulmón, } \\
\text { riñón, hígado y vejiga }\end{array}$ & $\begin{array}{l}\text { Fallo renal, osteoporosis, } \\
\text { anemia, cáncer en pulmón, } \\
\text { riñón, seno y próstata }\end{array}$ & $\begin{array}{l}\text { Neuro y nefrotoxicidad, alteraciones } \\
\text { psicomotoras, hipertensión, daño } \\
\text { cardiovascular y del sistema } \\
\text { hematológico; posible cáncer en } \\
\text { pulmón, estómago, cerebro y riñón }\end{array}$ \\
\hline
\end{tabular}

Tabla I. Toxicidad y factores metabólicos asociados con la ingestión de arsénico, cadmio y plomo. Fuente: Jaishankar, Tseten, Anbalagan, Mathew \& Beeregowda, 2014; Tchounwou, Yedjou, Patlolla \& Sutton, 2012.

apoptosis y promoviendo la transformación a células malignas (Achanzar et al., 2001; Schwerdtle et al., 2010).

Los metales pesados también compiten con elementos químicos que tienen funciones esenciales para los seres vivos (Malgieri et al., 2014). Esta competencia puede afectar, entre otras actividades orgánicas; el funcionamiento tanto de las enzimas metabólicas, como del sistema inmune; algunas funciones motoras; las interacciones proteína-proteína o proteína-ADN y rutas esenciales como la de generación de energía (Jaishankar, Tseten, Anbalagan, Mathew \& Beeregowda, 2014). Por ejemplo, el $\mathrm{Cd}^{2+}$ puede sustituir al $\mathrm{Zn}^{2+}$ en los sitios de unión de los denominados dedos de $\mathrm{Zn}^{2+}$, afectando la transcripción de la información genética; mientras que el arseniato de hidrógeno
$\left(\mathrm{HAsO}_{4}^{2-}\right)$ reemplaza al fosfato $\left(\mathrm{HPO}_{4}^{2-}\right)$ en reacciones bioquímicas, como la generación de ATP (Malgieri et al., 2014; Shen, Li, Cullen, Weinfeld \& Le, 2013).

Debido al impacto de los metales pesados en la salud humana, distintas instituciones alrededor del mundo han establecido límites máximos permisibles de $\mathrm{As}, \mathrm{Cd}$ y $\mathrm{Pb}$ en agua para consumo humano. La Agencia de Protección Ambiental de los Estados Unidos, establece como límites máximos $10 \mu \mathrm{g} / \mathrm{L}$ de As, $5 \mu \mathrm{g} / \mathrm{L}$ de Cd y $15 \mu \mathrm{g} / \mathrm{L}$ de Pb (USEPA, 2016). Estos mismos valores son reportados por la Organización Mundial de la Salud (OMS), la Administración de Medicamentos y Alimentos de los Estados Unidos de Norteamérica (FDA por sus siglas en inglés) y la Unión Europea (Council of 
the European Union, 1998; WHO., 2006; FDA, 2015). Con excepción del $\mathrm{Pb}$ en agua embotellada, donde el límite máximo es de $5 \mu \mathrm{g} / \mathrm{L}$ (FDA, 2010).

\section{BIOSORCIÓN DE METALES PESADOS}

El término sorción se refiere a un proceso físicoquímico que ocurre entre dos sustancias. Incluye tanto fenómenos de adsorción, como de absorción y se usa, entre otras cosas, para eliminar metales pesados (Gadd, 2008). La adsorción consiste en la unión de una molécula a una superficie, mientras que la absorción, implica que la molécula sea captada o internalizada (Fomina \& Gadd, 2014). El añadir el término "bio" a la palabra sorción, involucra el hecho de que se usarán compuestos de origen biológico, como sorbentes (Gadd, 2008). Su objetivo es disminuir la concentración de un sorbato (ej. metal pesado), en el medio aplicado (Fomina \& Gadd, 2014; Gadd, 2008). Los procesos de sorción en un material biológico son más complejos, ya que además de adsorción y absorción, involucran intercambio iónico, precipitación y acomplejamiento químico (Fomina \& Gadd, 2014).

La biosorción, como método de descontaminación, es una alternativa prometedora para descontaminar cuerpos de agua destinados a consumo humano. Puede emplearse en sustitución de los métodos físicos y químicos (ej. precipitación, coagulación/ floculación, filtración por membranas, etc.), que se usan para descontaminar efluentes industriales y resultan más eficientes para retiraraltas concentraciones de metales pesados (Lin \& Harichund, 2011; Rao, Mohapatra, Anand \& Venkateswarlu, 2010). Sin embargo, su uso en el retiro de bajas concentraciones, implica costos de operación elevados, utilización de grandes espacios y en algunas ocasiones, manejo o generación de sustancias tóxicas (Wang \& Chen, 2006). En cambio, la biosorción es eficiente para remediar la contaminación de agua para consumo, donde las concentraciones de metales son más bajas (1-100 mg/L), aunque de ninguna manera inocuas para la población (Council of the European Union, 1998; FDA, 2015; WHO, 2006).

\section{BIOMASA MICROBIANA PARA LA REMOCIÓN DE ARSÉNICO, CADMIO Y PLOMO}

Un biosorbente con potencial para remover metales pesados, es cualquier componente de origen biológico, capaz de atraer iones o moléculas contaminantes y retirarlas del medio que están contaminando. En general, son materiales renovables con gran disponibilidad y diversidad molecular; por ejemplo, biopolímeros como quitosano, pectinas, celulosa microcristalina y alginato, que pueden extraerse a bajo costo, o quedar como subproductos de la industria alimentaria (Purkayastha, Mishra \& Biswas, 2014). La biomasa vegetal y la microbiana, también sirven como biosorbente. Para el caso de la biorremediación del agua destinada a consumo, puede ser más conveniente el uso de aquellos microorganismos catalogados como inocuos o generalmente reconocidos como seguros ("Generally Recognized as Safe”, GRAS, por sus siglas en inglés), como bacterias acido-lácticas y levaduras (Kordialik-Bogacka \& Diowksz, 2014). La Figura 2 resalta algunos de los principales biosorbentes que se han estudiado para la remoción de $\mathrm{As}, \mathrm{Cd}$ y $\mathrm{Pb}$.

Diversos estudios demuestran que varias especies de Lactobacillus y de levaduras actúan como biosorbentes de $\mathrm{Ag}^{2+}, \mathrm{Cd}^{2+}, \mathrm{Co}^{2+}, \mathrm{Pb}^{2+}, \mathrm{Zn}^{2+}$ en soluciones acuosas (KordialikBogacka, 2014; Machado, Soares \& Soares, 2010; Monachese, 2012; Wang \& Chen, 2009; Zhang, Liu, Zhang, Wang \& Zhao, 2011). Entre las levaduras, los géneros más estudiados son Candida, Pichia, Cryptococcus y Saccharomyces, siendo esta última muy adecuada para descontaminar el agua para consumo humano, debido a su inocuidad (Wang \& Chen, 2009; Hernández Mata, Monge Amaya, Certucha Barragán, Almendariz Tapia \& Acedo Félix, 2013; Kulakovskaya et al., 2018).

\section{Ventajas de utilizar microorganismos como BIOSORBENTES}

Existen varias ventajas para utilizar biomasa microbiana como biosorbente. Destacan, el bajo costo energético requerido, un rango relativamente amplio de $\mathrm{pH}$ y temperaturas de operación, la recuperación de los metales en pequeños volúmenes y la posibilidad de reutilizar a la biomasa varias veces, después de eluir los metales adsorbidos. Una vez que la biomasa deja de ser efectiva puede biodegradarse o servir como fuente de carbono (Barakat, 2011; Rao, Mohapatra, Anand \& Venkateswarlu, 2010; Wang \& Chen, 2006). La rapidez con la que se lleva a cabo el proceso permite, además, descontaminar grandes volúmenes de agua (Wang \& Chen, 2006). Por otro lado, existe la posibilidad de mejorar la eficiencia de captación de metales, aplicando tratamientos físicos, químicos o sus combinaciones, para modificar la pared celular microbiana, aumentando la exposición de los grupos funcionales con los que interactúan (Gupta, Nayak \& Agarwal, 2015).

\section{MeCANISMOS de bIOSORCIÓN DEL ARSÉNICO, CADMIO Y PLOMO EN BIOMASA MICROBIANA}

Los mecanismos de biosorción que ocurren cuando la biomasa microbiana se pone en contacto con los metales pesados son básicamente dos: a) la absorción o internalización del metal a través de la membrana plasmática, también llamada bioacumulación y b) la unión a la pared celular del microorganismo, a través de procesos englobados en su conjunto como adsorción superficial que, además de la adsorción física, pueden incluir, intercambio iónico, microprecipitación y formación de complejos químicos por coordinación o quelación (Park, Yun \& Park, 2010). También ocurre microprecipitación en el interior de la célula (Park, Yun \& Park, 2010; Veglio \& Beolchini, 1997; Wang \& Chen, 2006). La bioacumulación y parte de la microprecipitación, dependen de que la biomasa esté viva; por ello se les clasifica dentro de los mecanismos metabólico-dependientes (Figura 3). El resto de los procesos son independientes del metabolismo, por lo que también 


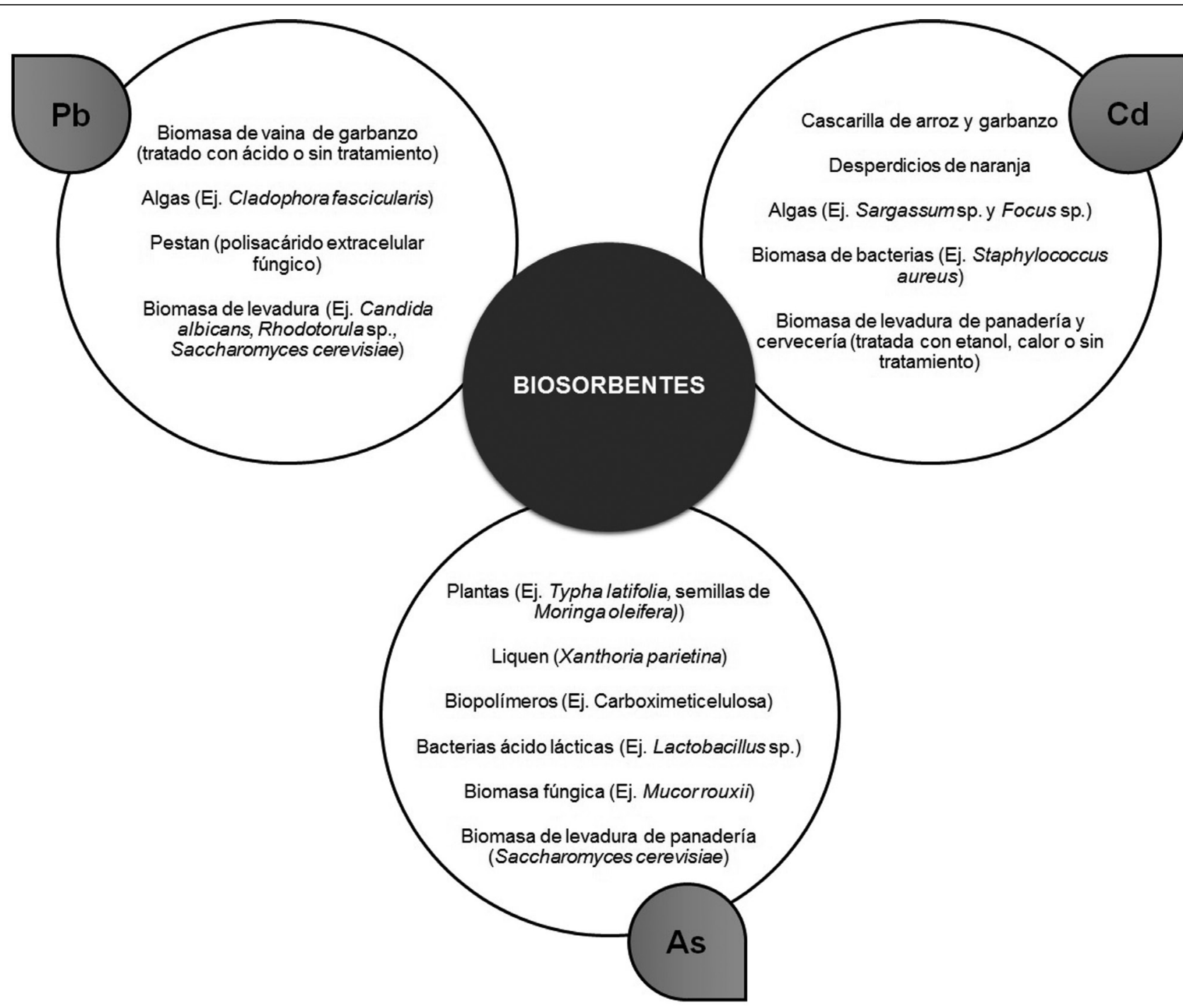

Figura 2. Biosorbentes estudiados con potencial para la remoción de plomo, cadmio y arsénico. Fuente: Arief, Trilestari, Sunarso, Indraswati \& Ismadji, 2008; Ahluwalia \& Goyal, 2007; Dhankhar \& Hooda, 2011; Hlihor et al., 2014; Yadanaparthi, Graybill \& von Wandruszka, 2009.

pueden llevarse a cabo utilizando biomasa muerta o inactiva (Park, Yun \& Park, 2010). Un proceso puede ser más favorable que otro, dependiendo, entre otras cosas, de las características fisicoquímicas del metal, de la complejidad de la estructura de la pared celular de la biomasa a utilizar, de su capacidad metabólica para neutralizar metales pesados y del estado físico de la biomasa (viva o muerta). Sin embargo, ello no excluye que los otros procesos se estén llevando a cabo simultáneamente, lo cual nos da una idea clara de la complejidad del fenómeno de biosorción (Rao, Mohapatra, Anand \& Venkateswarlu, 2010; Rao \& Prabhakar, 2011).

\section{BIOSORCIÓN POR BIOACUMULACIÓN}

Las levaduras bioacumulan metales pesados eficientemente; las vías de entrada a la célula son las permeasas y canales de transporte localizados en la membrana plasmática, que el microorganismo utiliza para captar metales esenciales como $\mathrm{Mn}^{2+}, \mathrm{Fe}^{2+}, \mathrm{Zn}^{2+}$, así como $\mathrm{SO}_{4}{ }^{2-}, \mathrm{PO}_{4}{ }^{2-}$ y algunos transportadores de glucosa y glicerol (Wysocki et al., 2001).

El As puede captarse como $\mathrm{As}^{3+} \mathrm{y} \mathrm{As}^{5+}$. La acuagliceroporina Fps 1p, es la vía de entrada para el arsenito $\left(\mathrm{As}^{3+}\right)$, mientras que el oxianión arsenato $\left(\mathrm{As}^{5+}\right)$, que es estructuralmente similar a los fosfatos, entra por las permeasas de fosfatos Pho84p y Pho89p (Wykoff \& Shea, 2001; Wysocki et al., 2001). Por su parte, el $\mathrm{Cd}^{2+}$ entra al citoplasma de las levaduras como Saccharomyces, a través de los canales proteicos que captan $\mathrm{Zn}^{2+}$ (Zrt1p), $\mathrm{Mn}^{2+}$ (Smflp, Smf2p), Fe ${ }^{2+}$ (Fet4p) y $\mathrm{Ca}^{2+}$ (Mid1p); además, el $\mathrm{Pb}^{2+}$ puede internalizarse a través de los canales para el calcio (Wysocki et al., 2001). 


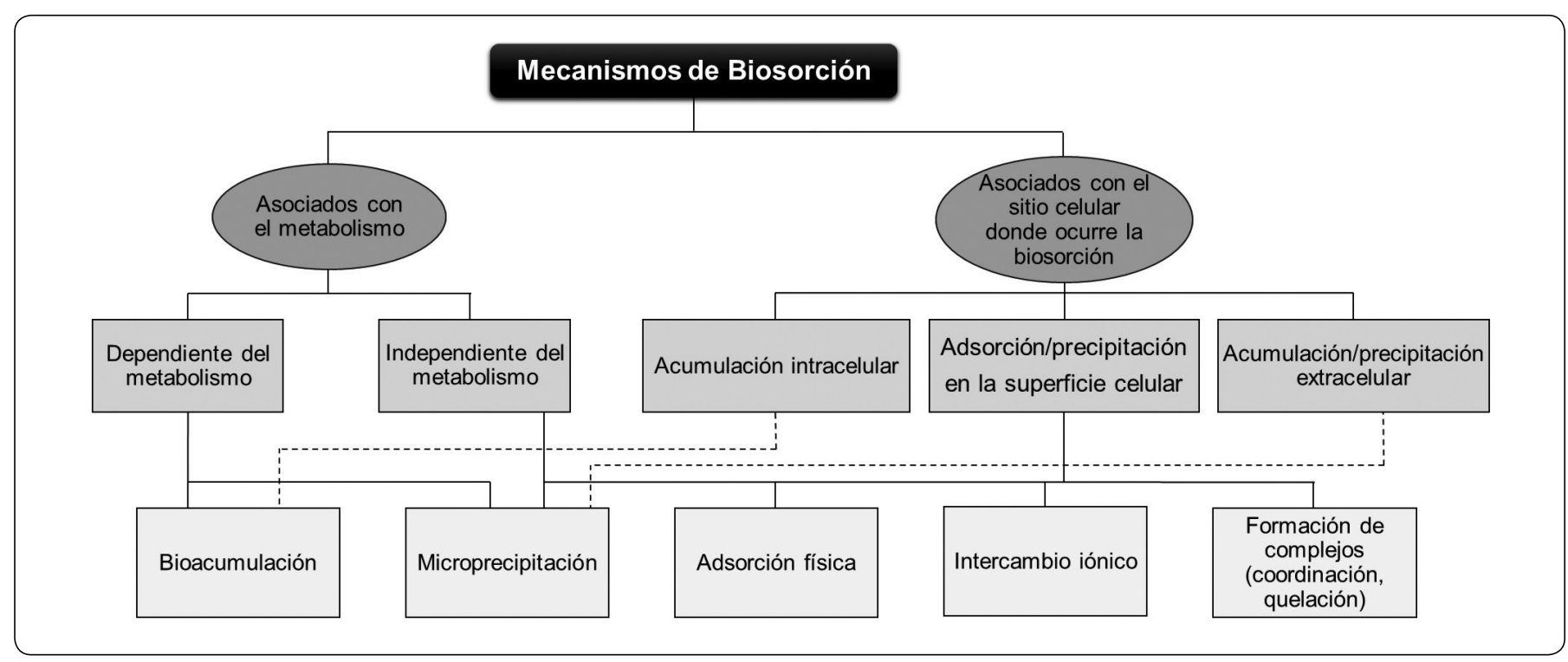

Figura 3. Clasificación de los procesos de biosorción con base en su asociación con el metabolismo y con el sitio donde ocurre la biosorción. Fuente: Modificado de Veglio \& Beolchini, 1997.

\section{BIOSORCIÓN POR INTERACCIÓN SUPERFICIAL}

La naturaleza compleja de la pared celular microbiana, permite que los metales se unan de diversas formas, principalmente interaccionando con los grupos carboxilato, fosfato, sulfhidrilo, amida e hidroxilo (Esposito, Pagnanelli \& Vegliò, 2002; Vasudevan, Padmavathy \& Dhingra, 2002). Las uniones se dan por: a) adsorción física a través de fuerzas de Van der Waals; b) intercambio iónico, donde un ion es sustituido o intercambiado por otro de la misma carga; la biomasa microbiana contiene metales ligeros como $\mathrm{Na}^{+}, \mathrm{Ca}^{2+}, \mathrm{K}^{+}$, $\mathrm{Mg}^{2+}$, unidos a grupos carboxilo, que pueden intercambiarse por otros metales. c) Formación de complejos (coordinación), cuando los cationes metálicos se combinan con los grupos funcionales de moléculas de la pared celular o con aniones que contienen pares de electrones libres (bases de Lewis), como $\mathrm{O}, \mathrm{N}$ o $\mathrm{S}$. En este caso, se establecen interacciones tanto electrostáticas, como covalentes, donde el metal pesado se designa como el átomo central (Wang \& Chen, 2006). Si ocurre la formación de complejos multi-dentados o multicoordinados, el metal puede quedar atrapado por quelación (Lin \& Harichund, 2011).

Los procesos de unión de los metales pesados a los grupos funcionales de la pared celular pueden ser simultáneos, aunque alguno de ellos puede predominar bajo ciertas condiciones, como se ha observado en otros tipos de biosorbentes (Chassary, Vincent, Macaskie \& Guibal, 2005; Zoghi, Khosravi-Darani \& Sohrabvandi, 2014). Por ejemplo, la quelación es más probable en condiciones cercanas a un $\mathrm{pH}$ básico, mientras que a medida que disminuye el $\mathrm{pH}$, es más probable que se dé el intercambio iónico.

\section{FACTORES AMBIENTALES QUE INFLUYEN EN LA BIOSORCIÓN DE METALES PESADOS POR LA BIOMASA MICROBIANA}

Existen diversos factores que influyen en la efectividad de la biomasa para remover metales pesados, que deben considerarse y estudiarse a fondo, antes de escalar un proceso de biosorción para fines industriales. En este sentido son importantes los factores tanto biológicos, como ambientales. Entre los factores biológicos encontramos: género, especie y cepa que se utilice; etapa de desarrollo celular y condiciones de cultivo. Todos estos factores influyen en la composición de la pared celular del microorganismo y por tanto, en el número de grupos funcionales que puedan interaccionar con el metal (Wang \& Chen, 2006). Entre los factores fisicoquímicos o ambientales que pueden afectar la biosorción se encuentran el pH y la temperatura, la concentración inicial del metal y sus propiedades químicas, así como el tiempo de contacto, la cantidad de biosorbente y la coexistencia de otros metales(Hlihor etal., 2014; Rao, Mohapatra, Anand \& Venkateswarlu, 2010). Cada uno de estos factores puede afectar la remoción de metales de diferente forma, por lo que su comprensión y control, puede llevar al establecimiento de las condiciones óptimas de desempeño de un biosorbente.

$\mathrm{PH}$

El pH es uno de los parámetros más importantes en el proceso de biosorción, ya que afecta tanto a los sitios funcionales de la biomasa, como a la química de los metales en solución. De hecho, los cambios de una unidad de $\mathrm{pH}$, pueden aumentar la biosorción de $0 \%$ a $100 \%$ (Muter et al., 2002). Lo anterior debido a que el $\mathrm{pH}$ también influye en el metal en términos de hidrólisis, acomplejamiento con compuestos orgánicos e inorgánicos presentes y potenciales redox (Fiol et al., 2006). 
Para metales pesados con carga positiva como $\mathrm{Cd}^{2+} \mathrm{y} \mathrm{Pb}^{2+}$, un pH más ácido genera mayor competencia con los iones hidronio por los sitios de unión en la pared celular de la biomasa y por tanto, menor eficiencia de remoción. Por otro lado, en $\mathrm{pH}$ básicos, la presencia de grupos hidroxilos puede generar la formación de complejos que habría que remover posteriormente (Hlihor et al., 2014). Lo ideal para retirar metales en agua para consumo es hacerlo cerca de $\mathrm{pH}$ neutros. Sin embargo, deben determinarse las capacidades de biosorción a diferentes $\mathrm{pH}$ para cada microorganismo con potencial de ser utilizado como biosorbente. Por ejemplo, S. cerevisiae absorbe mejor $\mathrm{Cd}^{2+} \mathrm{apH}$ entre 6.0 y 7.0; para el $\mathrm{Pb}^{2+}$ a pH 5.0, uranio a pH entre 4.0 y $5.0 \mathrm{y} \mathrm{Cu}^{2+}$ de 5.0 a 9.0 (Wang \& Chen, 2006; Zoghi, KhosraviDarani \& Sohrabvandi, 2014). Por otro lado, la fuerza iónica del solvente también tendrá una gran influencia en la capacidad de remoción, basada principalmente en competencia por los sitios de unión (Fomina \& Gadd, 2014).

\section{Concentración del metal y del biosorbente}

La concentración del metal funciona como la fuerza motriz necesaria para vencer la resistencia a la transferencia de masa de los iones, entre la superficie del biosorbente y la solución (Zoghi, Khosravi-Darani \& Sohrabvandi, 2014). Generalmente, la capacidad de biosorción aumenta al incrementarses la concentración del metal en la solución, debido a un mayor número de colisiones entre los iones metálicos y el biosorbente. Sin embargo, es importante encontrar la concentración adecuada para cada metal, ya que el número de grupos funcionales con los que interaccionan en la superficie celular es finito (Arief, Trilestari, Sunarso, Indraswati \& Ismadji, 2008).

Más que aumentar considerablemente la concentración del biosorbente, deben buscarse las condiciones adecuadas para que el área de exposición de estos grupos funcionales sea la mayor posible (Esposito, Pagnanelli \& Vegliò, 2002; Vasudevan, Padmavathy \& Dhingra, 2002). Si la concentración del biosorbente es muy elevada, podría producirse una superposición o agregación de los grupos funcionales, haciéndolos menos disponibles, ocasionando una disminución en la capacidad de remoción (Akar, Arslan, Alp, Arslan \& Akar, 2012).

\section{TIEMPO Y TEMPERATURA}

Los procesos de biosorción superficiales (adsorción, microprecipitación, intercambio iónico y acomplejamiento), requieren de tiempos cortos de exposición, mientras que si se pretende la captación del metal por biomasa viva, el proceso podrá durar varias horas (Wang \& Chen, 2006). Por lo tanto, puede llegar a ser más práctico utilizar biomasa inactiva, siempre y cuando no se requiera de algún proceso metabólico como sería la conversión del metal a una especie menos tóxica (Pokethitiyook \& Poolpak, 2016).

En general, la mayoría de los procesos de biosorción son temperatura-independientes; algunos pocos presentan reacciones exotérmicas y ocurren pocas excepciones, donde la temperatura puede afectar a la estabilidad del metal, la estabilidad del complejo metal-grupos funcionales de la pared celular o la ionización de los sitios de unión en la superficie de la célula (Özer \& Özer, 2003). En particular, S. cerevisiae biosorbe una mayor cantidad de metales, entre ellos, $\mathrm{Pb}$ y $\mathrm{Cr}$ a temperaturas cercanas a $25{ }^{\circ} \mathrm{C}$. Por el contrario, procesos a temperaturas mayores de $40{ }^{\circ} \mathrm{C}$ pueden provocar daños a la superficie del biosorbente, disminuyendo su eficiencia de remoción (Dhankhar \& Hooda, 2011).

\section{Presencia de otros metales}

En la práctica, el agua es una matriz muy compleja, donde coexisten diversos elementos y ligandos, dificultando el proceso de remoción dirigido hacia determinados metales pesados (Hlihor et al., 2014; Machado, Soares \& Soares, 2010). La existencia de otros metales pesados, así como otros iones $\left(\mathrm{K}^{+}, \mathrm{Na}^{+} \mathrm{Mg}^{+2}\right.$, etc. $)$ en el medio a descontaminar, se asocia a una disminución en la eficiencia de la biosorción, al generar competencia por los sitios de unión (Pokethitiyook \& Poolpak, 2016). Los aniones o ligandos inorgánicos que se encuentran más comúnmente en agua son sulfatos, carbonatos, cloruros, fosfatos y fluoruros, que pueden formar complejos con iones metálicos cargados positivamente, disminuyendo la capacidad de removerlos (Gadd, 2008). La afinidad entre estos iones puede explicarse a través de la teoría ácido-base duro-blando de Pearson (HSAB, por sus siglas en inglés). En ésta se establece que los iones clasificados como ácidos duros tienen afinidad por las bases duras, con uniones de tipo iónico; mientras que los ácidos blandos presentan afinidad por las bases blandas, a través de interacciones covalentes (Tabla II) (Pearson, 1963).

Además de esto, algunos microorganismos exhiben selectividad o incluso competencia en la remoción, cuando existe más de un metal pesado en solución (Wang \& Chen, 2006). El comportamiento en un sistema multicomponente, es uno de los principales desafíos a vencer para el exitoso funcionamiento y aplicación de un biosorbente, sobre todo en efluentes industriales, donde además las concentraciones son diversas y elevadas (Vijayaraghavan \& Balasubramanian, 2015).

\section{Saccharomyces cerevisiae COMO BIOSORBENTE DE METALES PESADOS}

Dentro de las levaduras del género Saccharomyces, S. cerevisiae es de especial interés como biosorbente. Es una levadura inocua, ampliamente utilizada en la industria alimentaria; la obtención de su biomasa es un proceso ampliamente industrializado y económico e incluso puede obtenerse como subproducto de los procesos de fermentación (Farhan \& Khadom, 2015). $S$. cerevisiae tiene la capacidad de remover metales pesados a bajas concentraciones, en soluciones acuosas, así como de tolerar cambios de $\mathrm{pH}$ y temperatura durante diferentes procesos (Rao \& Prabhakar, 2011; Veglio \& Beolchini, 1997; Wysocki et al., 2001). 


\begin{tabular}{|c|c|c|}
\hline DUROS & INTERMEDIOS & BLANDOS \\
\hline \multicolumn{3}{|c|}{ ÁCIDOS } \\
\hline $\begin{array}{c}\mathrm{H}^{+}, \mathrm{Na}^{+}>\mathrm{K}^{+} \\
\mathrm{Al}^{3+}>\mathrm{Ga}^{3+} \\
\mathrm{Y}^{3+}, \mathrm{REE}^{3+}(\mathrm{Lu}>\mathrm{La}) \\
\mathrm{Mo}^{6+}, \mathrm{W}^{6+}, \mathrm{U}^{6+} \\
\mathrm{Zr}^{++}, \mathrm{Nb}^{5+} \\
\end{array}$ & $\begin{array}{l}\mathrm{Fe}^{2+}, \mathrm{Mn}^{2+}, \mathrm{Cu}^{2+} \\
\mathrm{Zn}^{2+}>\mathrm{Pb}^{2+}, \mathrm{Sn}^{2+} \\
\mathrm{As}^{3+}>\mathrm{Sb}^{3+}=\mathrm{Bi}^{3+}\end{array}$ & $\begin{array}{c}\mathrm{Au}^{+}>\mathrm{Ag}^{+}>\mathrm{Cu}^{+} \\
\mathrm{Hg}^{2+}>\mathrm{Cd}^{2+} \\
\mathrm{Pt}^{2+}>\mathrm{Pd}^{2+}\end{array}$ \\
\hline \multicolumn{3}{|c|}{ BASES } \\
\hline $\begin{array}{c}\mathrm{F}^{-}, \mathrm{OH}^{-}, \mathrm{CO}_{3}^{2-}>\mathrm{HCO}_{3}^{-} \\
\mathrm{SO}_{4}^{2-}>\mathrm{HSO}_{4}^{-} \\
\mathrm{PO}_{4}^{3--}\end{array}$ & $\mathrm{Cl}^{-}$ & $\begin{array}{c}\mathrm{HS}^{-}>\mathrm{H}_{2} \mathrm{~S} \\
\mathrm{CN}^{-}, \mathrm{I}^{-}>\mathrm{Br}^{-}\end{array}$ \\
\hline
\end{tabular}

Tabla II. Clasificación de ácidos y bases de acuerdo a la teoría HSAB de Pearson (1963). Fuente: Pearson, 1963.

La biomasa de $S$. cerevisiae puede remover metales pesados, tanto si está metabólicamente activa (viva) o inactiva (muerta) (Fomina \& Gadd, 2014). Las ventajas de usar microorganismos inactivos incluyen prescindir de medios de cultivo y de nutrientes especiales, por lo que el costo se disminuye. Además, se posibilita la regeneración y reutilización de la biomasa, con opción de inmovilizarla y facilitar el modelado matemático de los fenómenos involucrados en la unión levadura-metal (Dhankhar \& Hooda, 2011).

\section{MeCanismo de interacción de leVaduRas INACtivas CON LOS METALES PESADOS}

El mecanismo de biosorción de las levaduras es complejo y no ha sido completamente elucidado, ya que influyen en él tanto factores intrínsecos, relacionados con la naturaleza de la superficie celular y las características químicas del metal, como extrínsecos, relacionados con $\mathrm{pH}$, fuerza iónica, etc. (Wang \& Chen, 2006). La pared celular de $S$. cerevisiae es un componente esencial para la unión del metal. Su carga superficial es negativa; a $\mathrm{pH}$ de 5.0 y 6.0 presenta un potencial zeta de $-27.7 \pm 1.0 \mathrm{mV}$ $\mathrm{y}-33.3 \pm 1.4 \mathrm{mV}$, respectivamente (Moreno-Rivas et al., 2016). Lo anterior nos indica que las interacciones predominantes serán con metales pesados que presenten la forma de cationes como $\mathrm{Cd}^{2+} \mathrm{y} \mathrm{Pb}^{2+}$.

La pared celular de $S$. cerevisiae está constituida principalmente por polisacáridos $(80 \%$ - 90\%). También se encuentran lípidos, proteínas, polifosfatos y algunos iones inorgánicos asociados. Se distinguen dos capas, la primera, exterior y más delgada, formada por una mezcla de glicanos, donde los glucanos $(\beta-1,3$ y $\beta-1,6)$ y mananos son los constituyentes más importantes. La segunda capa, interior y gruesa, está compuesta por polisacáridos fibrilares, como la quitina (Dhankhar \& Hooda, 2011).

Varios grupos funcionales de las moléculas de la pared celular interaccionan con los cationes metálicos, mediante interacciones electrostáticas. Entre ellos, carboxilos, hidroxilos, fosfatos y grupos tiol(Nagy, Tonk, Cerasella, Măicăneanu \& Majdik, 2013;
Park, Yun \& Park, 2010). También ocurre un intercambio iónico con grupos amidas, como lo demostraron Çabuk, Akar, Tunali \& Gedikli (2007), analizando la interacción $S$. cerevisiae con $\mathrm{Pb}^{2+}$ por espectroscopía infrarroja con trasformada de Fourier (FTIR). Además, mediante un análisis de espectroscopía de energía dispersiva, este mismo grupo de investigadores, encontró una reducción en la señal del fósforo, indicando una posible interacción por acomplejamiento del $\mathrm{Cd}^{2+}$ con los grupos fosfato de la superficie celular.

Por otra parte, la posibilidad de biosorción de As en agua para consumo, utilizando levadura inactiva es baja, debido a que el As disuelto en agua se encuentra principalmente en forma de aniones inorgánicos como arsenato y arsenito (Shankar, Shanker $\&$ Shikha, 2014). Se han identificado dos transportadores en $S$. cerevisiae que pueden captar $\mathrm{As}^{3+}$, mientras que el $\mathrm{As}^{5+}$ se internaliza a través del transportador de fosfato (Wang \& Chen, 2006). Sin embargo, Wu, Wen, Zhou, Dai \& Wu (2012), demostraron que la biomasa de levadura inactiva, proveniente de los subproductos de fabricación de cerveza, puede captar $\mathrm{As}^{3+}$ de soluciones acuosas, en función del $\mathrm{pH}$ del medio. La máxima biosorción se presentó a $\mathrm{pH}$ 5.0, siendo del 60\%. A este $\mathrm{pH}$ la especie predominante de $\mathrm{As}^{3+}$ en el medio acuoso es el $\mathrm{H}_{3} \mathrm{AsO}_{3}$ (sin carga). Por esta razón, no pueden establecerse interacciones electrostáticas con la pared de la levadura. Sin embargo, esta especie puede interactuar con los grupos aminos no protonados presentes en la pared. Esto debido a que el $\mathrm{H}_{3} \mathrm{AsO}_{3}$ se comporta como un ácido fuerte de Lewis, lo que le permite coordinarse con ligandos fuertes (base de Lewis), como los grupos amino y formar complejos mono y bidentados (Deng et al., 2016). A medida que aumenta el pH (6.0-10.0) disminuye la biosorción de As, ya que predomina la forma $\mathrm{H}_{2} \mathrm{AsO}_{3}{ }^{-}$, mientras que varios de los grupos funcionales de la pared celular se cargan negativamente produciendo una repulsión por igualdad de cargas (Kwok, Koong, Al Ansari \& McKay, 2018). En la Figura 4 se esquematizan los principales mecanismos propuestos para la biosorción de $\mathrm{Cd}^{2+}, \mathrm{Pb}^{2+} \mathrm{y}$ $\mathrm{H}_{3} \mathrm{AsO}_{3}$ 


\section{Adsorción}

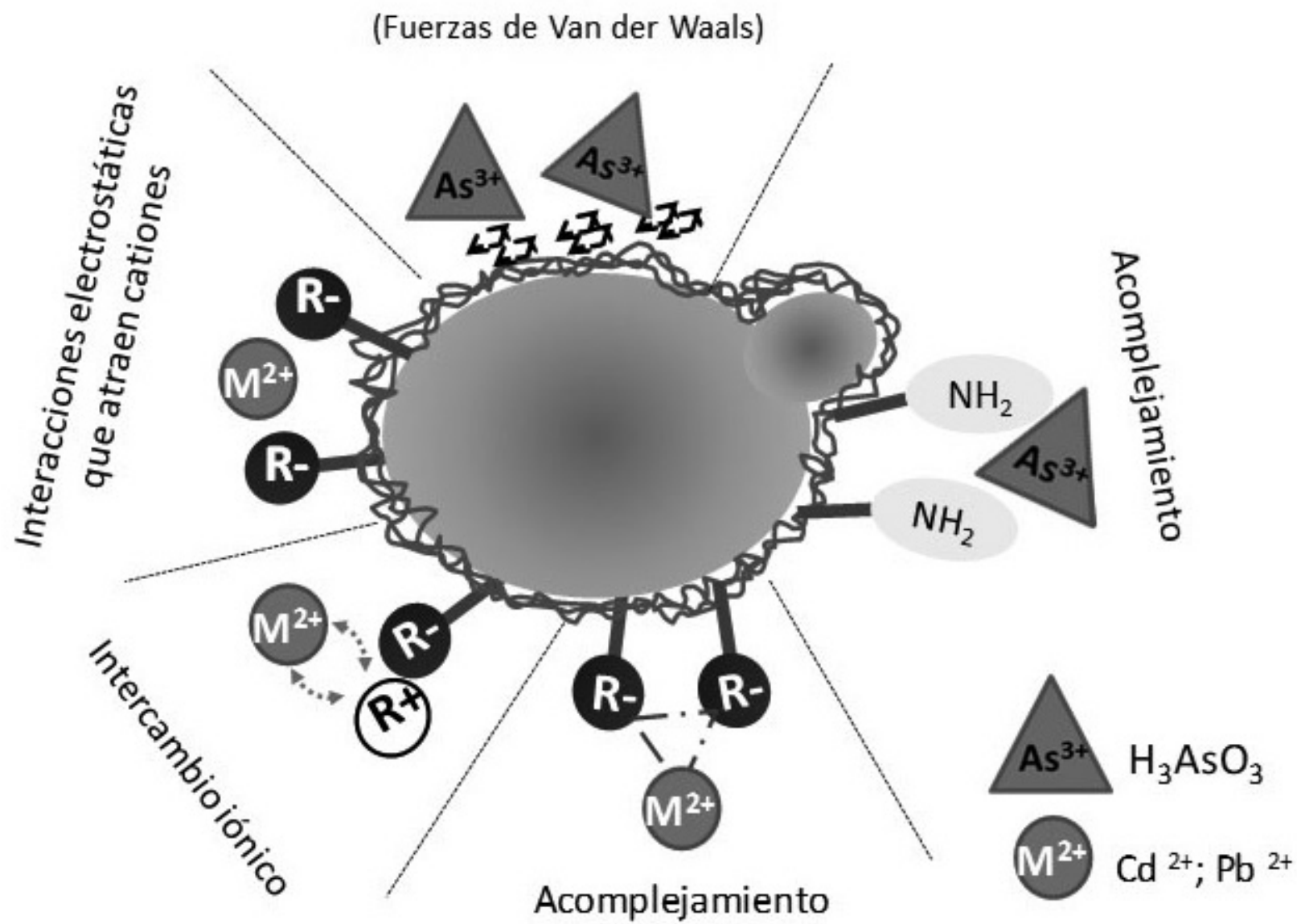

Figura 4. Interacciones que establecen los cationes metálicos con los grupos funcionales de la pared celular de S. cerevisiae. Fuente: Modificado de Niazi et al., 2016 y Zeraatkar et al., 2016.

\section{Capacidad de biosorción}

La capacidad de biosorción de metales por $S$. cerevisiae ha sido probada principalmente con $\mathrm{Pb}^{2+}, \mathrm{Cd}^{2+}, \mathrm{Zn}^{2+}, \mathrm{Cu}^{2+} \mathrm{Co}^{2+} \mathrm{y} \mathrm{Cr}^{2+}$ (Wang \& Chen, 2006). Farhan \& Khadom (2015), encontraron el siguiente orden en cuanto a capacidad de biosorción: $\mathrm{Pb}^{2+}$ $>\mathrm{Zn}^{2+}>\mathrm{Cr}^{2+}>\mathrm{Co}^{2+}>\mathrm{Cd}^{2+}>\mathrm{Cu}^{2+}$, atribuyéndose la unión, principalmente a grupos fosfato y carboxilos de la pared celular. Göksungur, Üren \& Güvenç (2005), analizaron la biosorción de $\mathrm{Cd}^{2+} \mathrm{y} \mathrm{Pb}^{2+}$ usando S. cerevisiae proveniente de los subproductos de la elaboración de cerveza. Para $\mathrm{Cd}^{2+}$, la máxima absorción $(15.38 \mathrm{mg} / \mathrm{g})$ ocurrió a $\mathrm{pH} 6.0$, mientras que para $\mathrm{Pb}^{2+}(15.59$ $\mathrm{mg} / \mathrm{g}$ ) fue a pH 5.0; en ambos casos, el tiempo de contacto fue de 5 min. Vasudevan, Padmavathy \& Dhingra (2003) encontraron comportamientos similares, con los mismos metales.

La eficiencia de remoción de $\mathrm{Cd}^{2+}$ por $S$. cerevisiae metabólicamente activo puede llegar hasta el $80 \%$, con tiempos de contacto de $120 \mathrm{~h}$ y una concentración inicial de
$\mathrm{Cd}^{2+}$ de $2 \mathrm{mg} / \mathrm{L}$. Del porcentaje total de remoción (80\%), 20\% correspondió a $\mathrm{Cd}^{2+}$ intracelular metabolizado por la levadura, indicando que la mayor captación ocurre en la pared celular (Wang \& Chen, 2006).

Roy, Gaur, Verma, Pathireddy \& Singh (2013) observaron que $S$. cerevisiae tiene capacidad de remover $\mathrm{As}^{3+}$ en agua en bajas concentraciones $(0.4 \mathrm{mg} / \mathrm{L})$, con un porcentaje máximo de remoción del 85.5\%, a pH 6.0. Estos estudios se realizaron con levadura metabólicamente activa, la cual captó una mayor cantidad de arsenito (hasta $90.5 \%$ ), cuando crecía en medios deficientes de nutrientes. Ello debido a una menor competencia por los sitios de unión en la pared celular.

Es importante resaltar que la naturaleza de la pared celular dictará la eficiencia de la captación de los metales, por lo que deben considerarse los factores que influyan en sus características, como la especie, cepa de la levadura y la fase de crecimiento 
en la que se llevará a cabo el proceso de biosorción (KordialikBogacka, 2011). Diversos estudios sobre la capacidad de biosorción de metales por S. cerevisiae y otros microorganismos, han encontrado que, en la fase de crecimiento exponencial, hay mayores porcentajes de remoción de metales pesados. Esto se atribuye a los cambios en la composición y estructura de la pared celular, que producen un aumento en las estructuras superficiales, lo que deriva en un mayor número de grupos carboxilos, fosfato y amino disponibles para unir metales (Kordialik-Bogacka, 2011; Roy, Gaur, Verma, Pathireddy \& Singh, 2013; Selvakumar et al., 2011).

\section{COMPARACIÓN DE LA CAPACIDAD DE BIOSORCIÓN DE S. cerevisiae CON OTROS BIOSORBENTES}

La biosorción de $\mathrm{Cd}^{2+}, \mathrm{Pb}^{2+} \mathrm{As}^{3+}$ y $\mathrm{As}^{5+}$ no se limita al uso de $S$. cerevisiae. Existe amplia investigación con bacterias, hongos y algas marinas. También, con subproductos orgánicos provenientes de la producción de alimentos; por ejemplo, subproductos de trigo, cáscara de coco, quitina transformada a quitosano, etc. (Gadd, 2008). La capacidad de biosorción de $\mathrm{Cd}^{2+}$ de la biomasa bacteriana inactiva es especie específica. Por ejemplo, la capacidad de biosorción de $\mathrm{mg} \mathrm{Cd}^{2+} / \mathrm{g}$ de biomasa seca de Aeromonas caviae fue de $155.3 \mathrm{mg} / \mathrm{g}$, mientras que la de Pseudomonas aeruginosa y Staphylococcus xylosus fueron de $42.4 \mathrm{mg} / \mathrm{g}$ y $250 \mathrm{mg} / \mathrm{g}$, respectivamente (Chang, Law \& Chang, 1997; Ziagova et al., 2007). Entre los hongos, el género Penicillium sp. ha sido de los más estudiados; Holan \& Volesky (1995) encontraron una capacidad de biosorción de $\mathrm{Cd}^{2+}$ de $56 \mathrm{mg} / \mathrm{g}$ para $P$. chrysogenum, mientras que Say, Yilmaz \& Denizli (2003), de $100.4 \mathrm{mg} / \mathrm{g}$ para P. purpurogenum. En el caso de Aspergillus niger, éste presentó capacidad de $1.31 \mathrm{mg} / \mathrm{g}$ y Trametes versicolor de $120.6 \mathrm{mg} / \mathrm{g}$ (Arıca, Kacar \& Genç, 2001). En comparación, la capacidad de biosorción de $\mathrm{Cd}^{2+} \mathrm{de}$ $S$. cerevisiae en diferentes experimentos se encontró en el rango de 20 hasta $90 \mathrm{mg} / \mathrm{g}$ (Wang \& Chen, 2009). Por otro lado, las algas marinas vivas presentan mayor capacidad para biosorber $\mathrm{Cd}^{2+}$ que S. cerevisiae (pardas $>$ verdes $>$ rojas $>$ S. cerevisiae) (Romera, González, Ballester, Blázquez, \& Muñoz, 2006). Sin embargo, ésta disminuye considerablemente al utilizar biomasa de alga muerta, lo que no ocurre con la levadura (Wang \& Chen, 2006; 2009).

Kogej \& Pavko (2001) compararon la capacidad de biosorción $\left(\mathrm{mg} \mathrm{Pb}{ }^{2+} / \mathrm{g}\right.$ de biomasa seca) de $S$. cerevisiae, con la de otros microorganismos, encontrando el siguiente patrón: Phanerochaete chrysosporium (419.4) > Rhizopus nigricans (403.2) > S. cerevisiae (211.2) >Aspergillus terreus (201.1) > Streptomyces clavuligerus (140.2). Bacillus firmus presentó una capacidad de $467 \mathrm{mg} \mathrm{Pb}^{2+} / \mathrm{g}$ de biomasa seca, mientras que la de $P$. aeruginosa y $P$. purpurogenum fue de 75.9 y 252.8 $\mathrm{mg} \mathrm{Pb}{ }^{2+} / \mathrm{g}$ de biomasa seca, respectivamente (Salehizadeh \& Shojaosadati, 2003; Say, Yilmaz \& Denizli, 2003; Chang, Law \& Chang, 1997). La comparación de la capacidad de biosorción de las algas marinas y $S$. cerevisiae siguió el mismo patrón que el mencionado para el $\mathrm{Cd}^{2+}$, aunque tanto las algas como la levadura, captan mayores cantidades de $\mathrm{Pb}^{2+}$ que de $\mathrm{Cd}^{2+}$ (Romera, González, Ballester, Blázquez \& Muñoz, 2006).

En lo que se refiere al $\mathrm{As}^{3+} \mathrm{y}$ al $\mathrm{As}^{5+}$, la mayoría de los estudios se han realizado con biomasa viva, en donde el fenómeno de bioacumulación es el que contribuye preponderantemente a la biosorción de arsenatos y arsenitos (Wang \& Zhao, 2009). Algunos estudios con biomasa inactiva se han realizado con sorgo, encontrándose capacidades de biosorción entre 2.4-2.8 $\mathrm{mg}$ de $\mathrm{As}^{3+} / \mathrm{g}$ de sorgo, después de $12 \mathrm{~h}$ de contacto, a un $\mathrm{pH}$ de 5.0 (Haque et al., 2007). Por otro lado, la biomasa inactiva proveniente de la planta Momordica charantia mostró una capacidad de biosorción de $0.88 \mathrm{mg} \mathrm{de} \mathrm{As}^{3+} / \mathrm{g}$ de planta, después de 45 min de exposición a un $\mathrm{pH}$ de 9.0 (Pandey, Choubey, Verma, Pandey, \& Chandrashekhar, 2009). La capacidad de biosorción de $\mathrm{As}^{3+}$ por S. cerevisiae fue menor que la encontrada en estos estudios; sin embargo, existe la posibilidad de protonar la pared celular de la levadura, para aumentar dicha capacidad (Wu, Wen, Zhou, Dai \& Wu, 2012; Safarik et al., 2015).

Los estudios mencionados indican que existen biosorbentes con mejor capacidad de biosorción para $\mathrm{Cd}^{2+}, \mathrm{Pb}^{2+} \mathrm{As}^{3+} \mathrm{yAs}^{5+}$ que la que presenta $S$. cerevisiae. Sin embargo, esta levadura presenta la ventaja de ser inocua, lo que mejora considerablemente la aceptación de su uso entre los posibles consumidores de agua sometida a biosorción o usuarios de filtros que contengan a este microorganismo. Otras ventajas del uso de levaduras son su bajo costo y amplia disponibilidad tanto a nivel comercial, como subproducto de la producción de algunas bebidas. El proceso de producción de levaduras a nivel industrial ha mejorado a través del tiempo, convirtiéndose en uno de los procesos biotecnológicos mejor controlados. Esto garantiza la disponibilidad constante de la levadura para diferentes fines industriales, incluido su uso potencial para la biosorción de metales pesados.

\section{ESTRATEGIAS PARA MEJORAR LA CAPACIDAD DE BIOSORCIÓN}

Se han probado diferentes estrategias para modificar la superficie de la levadura, a fin de mejorar su capacidad de biosorción. Por ejemplo, tratamientos térmicos de diferentes intensidades, cuyo objetivo es aumentar la exposición de sitios de unión(Ahluwalia \& Goyal, 2007). Otros tratamientos físicos incluyen la aplicación de microondas o de ondas ultrasónicas (sonicación). Entre los tratamientos químicos se encuentran tratamientos con álcalis, ácidos o solventes orgánicos (Fomina \& Gadd, 2014; Nagy, Tonk, Cerasella, Maicặneanu \& Majdik, 2013).

Machado, Janssens, Soares \& Soares (2009) estudiaron la capacidad de S. cerevisiae para remover $\mathrm{Ni}^{2+}, \mathrm{Cu}^{2+}$ y $\mathrm{Zn}^{2+}$, comparando levaduras metabólicamente activas, con otras inactivadas por calor. Encontraron una mayor remoción con la biomasa inactiva ( $44 \%$ - 50\%), utilizando tiempos de contacto entre 10 y $180 \mathrm{~min}$. Este comportamiento se atribuyó a la 
pérdida de integridad de la membrana plasmática, que produce una mayor exposición de grupos unidores de metales. Jianlong (2002), investigó la capacidad de biosorción del $\mathrm{Cu}^{2+}$, utilizando biomasa de $S$. cerevisiae modificada químicamente con metanol, formaldehído y glutaraldehído. En todos los casos encontró una disminución en la capacidad de biosorción, atribuida a la modificación de los grupos amino y carboxilo. Este estudio permitió conocer el papel fundamental que juegan estos grupos químicos, en la unión del metal a la pared celular.

Nagy, Tonk, Cerasella, Măicăneanu \& Majdik(2013) analizaron células de $S$. cerevisiae tratadas con irradiación por microondas y ondas ultrasónicas. Se observó una menor capacidad de remoción del $\mathrm{Cd}^{2+}$ en comparación con la biomasa control. Lo anterior, debido al daño provocado en los componentes de la pared celular, principalmente degradación de proteínas, mananos y glucanos, que son moléculas claves en la interacción. Sus resultados fueron confirmados por FTIR.

Una posibilidad interesante para utilizar levadura inactiva que capte arsénico, es la funcionalización de su pared celular, con cationes que interaccionen con oxianiones de $\mathrm{As}^{5+}$. En este sentido, Selvakumar et al. (2011) combinaron biomasa de $S$. cerevisiae carbonizada $\left(400^{\circ} \mathrm{C}\right)$, con nanopartículas de plata adheridas a su superficie, encontrando porcentajes de remoción de $\mathrm{As}^{5+}$ del $90 \%$ en un rango de $\mathrm{pH} 3.0$ a 5.0. Un proceso más sencillo fue propuesto por Rajesh-Kumar, Jayavignesh, Selvakumar, Swaminathan \& Ponpandian (2016), quienes magnetizaron la pared celular de la levadura con $\mathrm{Fe}_{3} \mathrm{O}_{4}$ encontrando eficiencias de remoción de $\mathrm{As}^{5+}$ del 70 al 95\%, al utilizar diferentes tiempos de contacto.

Otras modificaciones incluyen el uso de la biología molecular abordando el problema desde dos perspectivas. La primera, dirigida a aumentar la bioacumulación del metal, dentro del citoplasma, buscando la sobre-expresión de proteínas nativas unidoras de metales (p. e., metalotioneínas ricas en cisteínas) o de proteínas transgénicas como la fitoquelatina sintasa, para promover la síntesis de fitoquelatinas, capaces de unir metales pesados. Dicha estrategia aumentó hasta 6 veces la eficiencia de acumulación de $\mathrm{As}^{3+}$ en S. cerevisiae (Kuroda \& Ueda, 2010; Singh, Lee, DaSilva, Mulchandani \& Chen, 2008). La principal desventaja de estas modificaciones es que no permiten el reúso de la biomasa, ya que para recuperar los metales captados se requiere la destrucción de la célula (Gupta, 2015).

El segundo abordaje implica modificaciones genéticas en la superficie celular de la levadura, por ejemplo, para expresar proteínas ricas en histidina o cisteínas, las cuales aumentaron al doble la captación de $\mathrm{Cd}^{2+}$ (Vinopal, Ruml \& Kotrba, 2007). Sin embargo, para que estos organismos genéticamente modificados lleguen a utilizarse a nivel industrial, se requiere la aceptación tanto social, como legal, del uso de microorganismos transgénicos.

\section{Principales Retos a Vencer para utilizar la biosorCión MICROBIANA A NIVEL INDUSTRIAL}

La contaminación del agua de consumo con metales pesados es uno de los principales temas que influirán en el acceso al agua en un futuro cercano. Hasta el momento, las alternativas industriales de descontaminación utilizadas, son costosas y poco efectivas, cuando la contaminación es a bajas concentraciones. Además, de que en algunos casos, pueden generar otros problemas ambientales. Por su parte, la biosorción llevada a cabo por microorganismos, es una alternativa más amigable con el medio ambiente, que presenta la ventaja de ser, rápida, selectiva, barata y altamente disponible. Sin embargo, su aplicación a nivel industrial no se ha concretado efectivamente, debido a una serie de retos que se discuten a continuación.

\section{Sensibilidad al pH y efecto de la presencia de otros IONES}

Como se indicó anteriormente, el $\mathrm{pH}$ tiene gran influencia en el proceso de biosorción porque influye en la carga de los grupos funcionales de la pared celular y, por tanto, en las interacciones que puedan establecer con los metales pesados (Wang \& Chen, 2006). Los pH, entre 6.0 y 6.8 son ideales para que la superficie de $S$. cerevisiae esté cargada negativamente, interaccionando mejor con $\mathrm{Pb}$ y $\mathrm{Cd}$. A pH muy bajos, es más factible la interacción con arsenatos y arsenitos que tienen carga negativa (Monachese, 2012).

Por otro lado, iones comúnmente presentes en los efluentes industriales como $\mathrm{Ca}, \mathrm{Zn}$ y $\mathrm{Mg}$, pueden competir por unirse a los grupos funcionales de la levadura (Rao, Mohapatra, Anand $\&$ Venkateswarlu, 2010). El uso de métodos híbridos es una alternativa prometedora para resolver estos problemas. Es decir, usar tecnologías convencionales, o métodos electroquímicos, combinados con la biosorción (Gupta, Nayak \& Agarwal, 2015). Sin embargo, debe garantizarse el tratamiento de los efluentes industriales antes de la descarga a los cuerpos de agua. De esta manera, se puede implementar un método que elimine iones que puedan competir con los metales pesados, ajustar el $\mathrm{pH}$ y aplicar la biosorción con la levadura, a fin de eliminar las concentraciones residuales de metales pesados, que tanto afectan a la salud. En este sentido, es necesario establecer las condiciones en que la levadura pueda biosorber la mayor cantidad $\mathrm{de} \mathrm{Cd}$, As y $\mathrm{Pb}$ al mismo tiempo. Por ejemplo, la biomasa puede magnetizarse con moléculas que contengan hierro, para mejorar la captación de arsénico (Yin, Wang, Yang \& Li, 2016).

\section{NeCesidad de PROCESOS CONTINUOS}

Para que el proceso de biosorción sea escalable a nivel industrial debe ser continuo. Ello implica el uso de biorreactores o columnas reusables a través de las cuales se haga pasar el agua a descontaminar (Park, Yun \& Park, 2010). Las columnas fijas, en donde se empaca una cama de biosorbente y las de cama fluidizada, donde el biosorbente puede expandirse a través de la 
columna, son los biorreactores con mayor potencial (CañizaresVillanueva, 2000, Gupta, Nayak \& Agarwal, 2015). Sin embargo, el tamaño tan pequeño de las células microbianas, así como su limitada fuerza mecánica y baja resistencia a las presiones hidrostáticas, provocan, desintegración celular, pérdida de eficiencia en la remoción y problemas para separar a la biomasa del agua tratada a pesar del uso de cepas floculantes (Park, Yun \& Park, 2010; Rosca et al., 2015).

Una alternativa para evitar estos problemas es establecer un sistema adecuado para inmovilizar a la biomasa, que le dé soporte, evite su degradación y permita la posibilidad de regeneración de la columna (Gupta, Nayak \& Agarwal, 2015). Entre los materiales más empleados como matrices de inmovilización se encuentran el alginato, la sílica, la poliacrilamida y la polisulfona, donde la biomasa puede ser adsorbida, encapsulada o entrecruzada mediante reacciones químicas (Cañizares-Villanueva, 2000; Vijayaraghavan \& Balasubramanian, 2015). Marques, Pinheiro \& Rosa (2007) estudiaron la capacidad de remoción de $\mathrm{Cd}^{2+}$ por $S$. cerevisiae inmovilizada en poliuretano, dentro de un reactor de lecho fluidizado, tipo airlift, encontrando capacidades máximas de remoción de $7.06 \mathrm{mmol} \mathrm{Cd} / \mathrm{g}$ de biosorbente. Esta capacidad fue mayor a la encontrada en reactores de columna fija $(1.90 \mathrm{mmol}$ $\mathrm{Cd} / \mathrm{g}$ biosorbente), atribuyéndose el resultado a la mayor área de exposición de grupos funcionales en la biomasa contenida en el airlift, como se aprecia en la Figura 5.

La elección de la matriz y del método de inmovilización es crucial para el éxito del escalamiento del proceso. Entre los factores a considerar para elegir una matriz se encuentran: costo, disponibilidad, facilidad de manejo, sustentabilidad

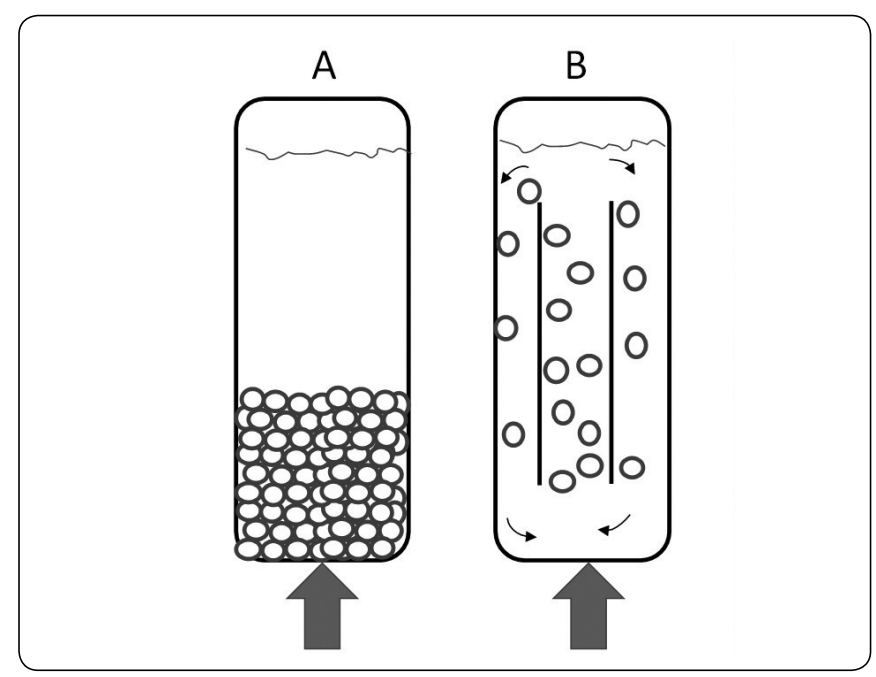

Figura 5. Representación esquemática de la inmovilización de biomasa para mejorar el proceso de biosorción a) columna fija y b) columna de lecho fluidizado tipo airlift. Los círculos representan cápsulas cargadas con $S$. cerevisiae. Fuente: Modificado de Levenspiel, 1984 y Spence \& Bailon, 2000. y resistencia. La Tabla III resume ventajas y desventajas de las principales técnicas de inmovilización. La resistencia a la transferencia de masas es una de las desventajas más importantes, ya que aumenta el tiempo de biosorción y por tanto, el costo del proceso. Es importante realizar estudios para lograr la porosidad y resistencia más adecuadas, considerando el flujo hidráulico en el reactor y la resistencia de masa, de tal manera que se encuentre un verdadero costo-beneficio para el proceso de biosorción (Amirnia, Ray \& Margaritis, 2015; Fomina \& Gadd, 2014).

Actualmente, existen algunos biosorbentes comerciales como BIO-FIX, que es una mezcla de algas, bacterias y levadura, en una matriz polimérica de polisulfona; AMT-Bioclaim es un producto granulado de biomasa de Bacillus subtilis inmovilizada en polietilenimina entrecruzada con glutaraldehído; AlgaSORB, biomasa de Chlorella vulgaris inmovilizada en una matriz de sílica y B.V. Sorbex, obtenido de biomasa de microalgas (Cañizares-Villanueva, 2000; Dhankhar \& Hooda, 2011; Fomina \& Gadd, 2014; Gupta, Nayak \& Agarwal, 2015). Sin embargo, no existe un biosorbente comercial que use únicamente biomasa de levadura, ni los biosorbentes mencionados tienen aplicación práctica en la actualidad (Gupta, Nayak \& Agarwal, 2015).

\section{Destino de la biomasa después de LA BIOSORCión}

Después del proceso de biosorción el agua puede quedar libre de metales pesados o con concentraciones por debajo de las normas internacionales. Se resuelve el problema del agua, pero queda el de qué hacer con la biomasa, ya que desecharla, solo resultaría en transferir la contaminación. La regeneración es uno de los posibles procedimientos y consiste en recuperar los metales pesados bioadsorbidos en la pared de las levaduras (Wang \& Chen, 2006). El tratamiento debe ser suficientemente fuerte, para desprender o eluir los metales y suficientemente suave, para no dañar a los ligandos de la pared celular, conservando la eficiencia de la biomasa para que pueda volver a utilizarse. Esta operación puede aplicarse únicamente cuando se usa biomasa muerta, ya que la bioacumulación implicaría destruir a las células para recuperar a los metales internalizados hacia el citoplasma (Gupta, Nayak \& Agarwal, 2015).

La información acerca de la regeneración de biosorbentes en procesos continuos es escasa. Los datos disponibles sobre procesos en lote o discontinuos indican que, con los métodos aplicados hasta el momento, los ciclos de reutilización de la biomasa son limitados (Hammaini, González, Ballester, Blázquez \& Muñoz, 2007; Mata, Blázquez, Ballester, González $\&$ Muñoz, 2010). Por otro lado, para que el proceso sea costeable, debe generarse un volumen mínimo de eluato, que concentre al metal 100 o más veces (Naja, Murphy \& Volesky, 2010).

Entre los regenerantes más utilizados se encuentran compuestos quelantes como el EDTA; sulfatos, carbonatos, hidróxidos y 


\begin{tabular}{|c|c|c|c|}
\hline Método & Matriz & Ventajas & Desventajas \\
\hline $\begin{array}{l}\text { Adsorción } \\
\text { físicoquímica } \\
\text { Interacciones } \\
\text { reversibles }\end{array}$ & $\begin{array}{l}\text { Carbón activado } \\
\text { sílica, nanoestructurados de } \\
\text { carbón, cerámicas, arcillas }\end{array}$ & $\begin{array}{c}\text { Gran densidad de biomasa } \\
\text { adsorbida }\end{array}$ & $\begin{array}{l}\text { Uniones inestables provocan el } \\
\text { desprendimiento de biomasa }\end{array}$ \\
\hline $\begin{array}{l}\text { Encapsulamiento en } \\
\text { matrices biológicas }\end{array}$ & $\begin{array}{c}\text { Gelatina, alginato, } \\
\text { quitosano, celulosa y sus } \\
\text { derivados; combinaciones } \\
\text { de varias matrices } \\
\end{array}$ & $\begin{array}{l}\text { Ecológicamente amigables, } \\
\text { algunas también con } \\
\text { capacidad de biosorción }\end{array}$ & $\begin{array}{l}\text { Las cápsulas pueden perder estabilidad } \\
\text { y hacerse más frágiles con el reúso }\end{array}$ \\
\hline $\begin{array}{l}\text { Encapsulamiento en } \\
\text { matrices sintéticas }\end{array}$ & $\begin{array}{l}\text { Polivinilsulfonas, } \\
\text { poliacrilamida } \\
\text { polietilenamina } \\
\end{array}$ & $\begin{array}{l}\text { Atrapa la biomasa } \\
\text { protegiéndola de presiones } \\
\text { hidrostáticas elevadas }\end{array}$ & Resistencia a la transferencia de masa \\
\hline Entrecruzamiento & $\begin{array}{l}\text { Formaldehído, } \\
\text { glutaraldehído, } \\
\text { divinilsulfona }\end{array}$ & $\begin{array}{l}\text { Aumenta la resistencia de } \\
\text { la biomasa a la presión } \\
\text { hidrodinámica }\end{array}$ & $\begin{array}{l}\text { Resistencia a la transferencia de masa; } \\
\text { debe asegurarse la eliminación de } \\
\text { residualidad de los entrecruzantes } \\
\text { debido a que son sustancias tóxicas; } \\
\text { en algunas ocasiones se observa } \\
\text { disminución de la eficacia de biosorción }\end{array}$ \\
\hline
\end{tabular}

Tabla III. Ventajas y desventajas de algunos métodos de inmovilización de biomasa microbiana para la biosorción de metales pesados. Fuente: Modificada de Fosso-Kankeu \& Mulaba-Bafubiandi (2014).

cloruros; además, ácidos muy diluidos $(\leq 100 \mathrm{mM})$ como los ácidos acético, nítrico y sulfúrico (Soares \& Soares, 2012). Se necesitan estudios para conocer las mejores condiciones de uso y el número de ciclos de regeneración efectivos, al utilizar levaduras inmovilizadas. Además de relacionarlos con los costos de operación para determinar su conveniencia. Una revisión detallada sobre los métodos de regeneración utilizados para remover metales pesados, indica que la gran mayoría de las investigaciones no contempla su impacto ecológico (Lata, Singh \& Samadder, 2015). También se requieren estudios sobre la inocuidad del agua obtenida después de varios ciclos de regeneración, que garanticen la completa remoción de los eluyentes utilizados. Es un requisito certificar la inocuidad del agua (tanto química como microbiológica), después de los procesos de biosorción/regeneración (Dubey, Gopal \& Bersillon, 2009).

Otro posible destino de la biomasa es la incineración; cuando se aplica a $500{ }^{\circ} \mathrm{C}$, el peso de la biomasa se reduce hasta $83 \%$ y $98 \%$, cuando los tiempos de incineración son de 15 min y $4 \mathrm{~h}$, respectivamente (Machado, Soares \& Soares, 2010). Si no existe interés en recuperar el metal, la ceniza puede inmovilizarse o contenerse en un lugar seguro. Alternativamente los metales pueden recuperarse selectivamente utilizando soluciones ácidas, electrodeposición y precipitación alcalina. Sin embargo, esto se ha estudiado únicamente en la recuperación de metales de interés como Zn, Ni y Cu (Soares \& Soares, 2012). En el caso de As, $\mathrm{Cd}$ y $\mathrm{Pb}$, son necesarios estudios económicos para determinar la factibilidad del proceso de incineración vs. regeneración de la biomasa.

\section{Conclusiones}

El método de biosorción con $S$. cerevisiae para la descontaminación de metales pesados es una alternativa prometedora para eliminar bajas concentraciones de $\mathrm{As}^{+3}, \mathrm{As}^{+5}$, $\mathrm{Cd}^{2+} \mathrm{y} \mathrm{Pb}^{2+}$ en agua para consumo. Sin embargo, la mayoría de los progresos actuales se conservan a nivel de laboratorio. Es necesario optimizar las condiciones para su uso en gran escala y explorar otras posibilidades, como la inmovilización por encapsulamiento y el uso de tecnologías híbridas, que combinen la biosorción con otros procesos tradicionales, a fin de optimizar el proceso.

\section{Agradecimientos}

Los autores agradecen al Consejo Nacional de Ciencia y Tecnología (CONACYT) por el financiamiento otorgado bajo el proyecto CB-2011-169658 y la beca a la estudiante de doctorado Silvia Carolina Moreno Rivas.

\section{Referencias}

Achanzar, W. E., Diwan, B. A., Liu, J., Quader, S. T., Webber, M. M., \& Waalkes, M. P. (2001). Cadmium-induced Malignant Transformation of Human Prostate Epithelial Cells. Cancer Research, 61(2), 455-458.

Ahluwalia, S. S., \& Goyal, D. (2007). Microbial and plant derived biomass for removal of heavy metals from wastewater. Bioresource Technology, 98(12), 2243-2257. http://doi.org/10.1016/j. biortech.2005.12.006

Akar, S. T., Arslan, S., Alp, T., Arslan, D., \& Akar, T. (2012). Biosorption potential of the waste biomaterial obtained from 
Cucumis melo for the removal of $\mathrm{Pb}^{2+}$ ions from aqueous media: equilibrium, kinetic, thermodynamic and mechanism analysis. Chemical Engineering Journal, 185-186, 82-90. http://doi. org/10.1016/j.cej.2012.01.032

Amirnia, S., Ray, M. B., \& Margaritis, A. (2015). Heavy metals removal from aqueous solutions using Saccharomyces cerevisiae in a novel continuous bioreactor-biosorption system. Chemical Engineering Journal, 264, 863-872. http://doi.org/10.1016/j.cej.2014.12.016

Arıca, M. Y., Kacar, Y., \& Genç, Ö. (2001). Entrapment of white-rot fungus Trametes versicolor in Ca-alginate beads: preparation and biosorption kinetic analysis for cadmium removal from an aqueous solution. Bioresource technology, 80(2), 121-129.

Arief, V. O., Trilestari, K., Sunarso, J., Indraswati, N., \& Ismadji, S. (2008). Recent progress on biosorption of heavy metals from liquids using low cost biosorbents: characterization, biosorption parameters and mechanism studies. Clean, 36(12), 937-962. http:// doi.org/10.1002/clen.200800167

Armah, F. A., Quansah, R., \& Luginaah, I. (2014). A systematic review of heavy metals of anthropogenic origin in environmental media and biota in the context of gold mining in Ghana. International Scholarly Research Notices, 252148. http://doi. org/10.1155/2014/252148

Arreguín Cortés, F. I., Chávez Guillén, R., Soto Navarro, P. R., \& Smedley, P. L. (2010). Una revisión de la presencia de arsénico en el agua subterránea en México. Revista Tláloc AMH, 45, 1-11.

Bandyopadhyay, D., Ghosh, D., Chattopadhyay, A., Firdaus, S. B., Ghosh, A. K., Paul, S., Bhowmik, D., Mishra, S., \& Dalui, K. (2014). Lead induced oxidative stress: a health issue of global concern. Journal of Pharmacy Research, 8(9), 1198-1207.

Barakat, M. A. (2011). New trends in removing heavy metals from industrial wastewater. Arabian Journal of Chemistry, 4(4), 361377. http://doi.org/10.1016/j.arabjc.2010.07.019

Çabuk,A.,Akar, T., Tunali, S. \& Gedikli, S. (2007. Biosorption of Pb(II) by industrial strain of Saccharomyces cerevisiae immobilized on the biomatrix of cone biomass of Pinus nigra: Equilibrium and mechanism analysis. Chemical Engineering Journal, 131(1), 293-300. DOI: https://doi.org/10.1016/j.cej.2006.12.011

Cañizares-Villanueva, R. O. (2000). Biosorción de metales pesados mediante el uso de biomasa microbiana. Revista Latinoamericana de Microbiología, 42, 131-143.

Central Pollution Control Board, C. P. C. B. (2007). Cadmium an environment toxicant. Recuperado de http://cpcb.nic. in/upload/Newsletters/Newsletters_61_CADMIUM-An EnvironmentToxicant-March-2007.pdf

Chang, J. S., Law, R., \& Chang, C. C. (1997). Biosorption of lead, copper and cadmium by biomass of Pseudomonas aeruginosa PU21. Water research, 31(7), 1651-1658.

Chassary, P., Vincent, T., Macaskie, L. E., \& Guibal, E. (2005). Palladium and platinum recovery from bicomponent mixtures using chitosan derivatives. Hydrometallurgy, 76, 131-147. http:// doi.org/10.1016/j.hydromet.2004.10.004

Chowdhury, S., Mazumder, M.A. J.,Al-Attas, O., \& Husain, T. (2016). Heavy metals in drinking water: Occurrences, implications, and future needs in developing countries. Science of The Total
Environment, 569-570, 476-488. doi:https://doi.org/10.1016/j. scitotenv.2016.06.166

Council of the European Union. (1998). Council Directive 98/83/Ec Official Journal of the European Communities, L 330, 32-54.

Deng, S., Zhang, G., Chen, S., Xue, Y., Du, Z., \& Wang, P. (2016). Rapid and effective preparation of a HPEI modified biosorbent based on cellulose fiber with a microwave irradiation method for enhaced arsenic removal in water. Journal of Materials Chemistry A, 4(41), 15851-15860.

Dhankhar, R., \& Hooda,A. (2011). Fungal biosorption - an alternative to meet the challenges of heavy metal pollution in aqueous solutions. Environmental Technology, 32(5), 467-491. http://doi.org/10.10 80/09593330.2011.572922

Dubey, S. P., Gopal, K., \& Bersillon, J. L. (2009). Utility of adsorbents in the purification of drinking water: a review of characterization, efficiency and safety evaluation of various adsorbents. Journal of Environmental Biology, 30(3), 327-332.

Duffus, J. H. (2002). Heavy metals - a meaningless term? (IUPAC Technical Report). Pure Applied Chemistry, 74(5), 793-807.

Esposito, A., Pagnanelli, F., \& Vegliò, F. (2002). pH-related equilibria models for biosorption in single metal systems. Chemical Engineering Science, 57, 307-313.

Farhan, S. N., \& Khadom, A. A. (2015). Biosorption of heavy metals from aqueous solutions by Saccharomyces cerevisiae. International Journal of Industrial Chemistry, 6(2), 119-130. http://doi.org/10.1007/s40090-015-0038-8

FDA. U.S. Food and Drug Administration. (2010). Bottled Water Everywhere: Keeping it Safe.FDA Consumer Health Information, (June), 1-2.

FDA. U.S. Food and Drug Administration. (2015). Beverages. Food for Human Consumption. Recuperado de https://www.accessdata. fda.gov/scripts/cdrh/cfdocs/cfcfr/CFRSearch.cfm?fr=165.110

FPTCDW (Federal-Provincial-Territorial Committee on Drinking Water) 2006. Guidelines for Canadian Drinking Water Quality. Guideline Technical Document: Arsenic. Health Canada: Ottawa.

Ferreira, V., Koricheva, J., Duarte, S., Niyogi, D. K., \& Guérold, F. (2016). Effects of anthropogenic heavy metal contamination on litter decomposition in streams - a meta-analysis. Environmental Pollution, 210, 261-270. http://doi.org/10.1111/brv.12125

Fiol, N., Villaescusa, I., Martínez, M., Miralles, N., Poch, J., \& Serarols, J. (2006). Sorption of $\mathrm{Pb}(\mathrm{II}), \mathrm{Ni}(\mathrm{II}), \mathrm{Cu}(\mathrm{II})$ and $\mathrm{Cd}(\mathrm{II})$ from aqueous solution by olive stone waste. Separation and Purification Technology, 50, 132-140. http://doi.org/10.1016/j. seppur.2005.11.016

Fomina, M., \& Gadd, G. M. (2014). Biosorption: current perspectives on concept, definition and application. Bioresource Technology, 160, 3-14. http://doi.org/10.1016/j.biortech.2013.12.102

Fosso-Kankeu, E., \& Mulaba-Bafubiandi, A. (2014). Review of challenges in the escalation of metal-biosorbing processes for wastewater treatment: Applied and commercialized technologies. African Journal of Biotechnology, 13(17), 1756-1771. http://doi. org/10.5897/AJB2013.13311

Gadd, G. M. (2008). Biosorption: critical review of scientific rationale, environmental importance and significance for pollution treatment. 
Journal of Chemical Technology and Biotechnology, 84(1), 13-28. http://doi.org/10.1002/jctb.1999

García-Esquinas, E., Pollan, M., Umans, J. G., Francesconi, K. A., Goessler, W., Guallar, E., Howard, B., Farley, J., Best, L. G., \& Navas-Acien, A. (2013). Arsenic exposure and cancer mortality in a US-based prospective cohort: the strong heart study. Cancer Epidemiology Biomarkers and Prevention, 22(11), 1944-1953. http://doi.org/10.1158/1055-9965.EPI-13-0234-T

Göksungur,Y., Üren, S., \& Güvenç,U.(2005). Biosorption of cadmium and lead ions by ethanol treated waste baker's yeast biomass. Bioresource Technology,96(1), 103-109. http://doi.org/10.1016/j. biortech.2003.04.002

Gupta, V. K., Nayak, A., \& Agarwal, S. (2015). Bioadsorbents for remediation of heavy metals: current status and their future prospects. Environmental Engineering Research, 20(1), 1-18.

Hammaini, A., González, F., Ballester, A., Blázquez, M. L., \& Muñoz, J. A. (2007). Biosorption of heavy metals by activated sludge and their desorption characteristics. Journal of Environmental Management, 84(4), 419-426. DOI:https://doi.org/10.1016/j. jenvman.2006.06.015

Haque, M. N., Morrison, G. M., Perrusquia, G., Gutierrez, M., Aguilera, A. F., Cano-Aguilera, I., \& Gardea-Torresdey, J. L. (2007). Characteristics of arsenic adsorption to sorghum biomass. Journal of hazardous materials, 145(1-2), 30-35.

Hartwig, A. (2013). Cadmium and cancer. Met Ions Life Sci, 11, 491 507. DOI:10.1007/978-94-007-5179-8 15

Hernández Mata, K. M., Monge Amaya, O., Certucha Barragán, M. T., Almendariz Tapia, F. J., \& Acedo Félix, E. (2013). Metallic biosorption using yeasts in continuous systems. International Journal of Photoenergy, 4. http://dx.doi.org/10.1155/2013/578729

Hlihor, R. M., Bulgariu, L., Sobariu, D. L., Diaconu, M., Tavares, T., \& Gavrilescu, M. (2014). Recent advances in biosorption of heavy metals: support tools for biosorption equilibrium, kinetics and mechanism. Revue Roumaine de Chimie, 59(6-7), 527-538.

Holan, Z. N., \& Volesky, B. N. (1995). Accumulation of cadmium, lead, and nickel by fungal and wood biosorbents. Applied biochemistry and biotechnology, 53(2), 133-146.

IARC. (2016). Agents classified by the IARC monographs. Volumes 1-115. Lyon, France. Recuperado de http://monographs.iarc.fr/ ENG/Classification/latest_classif.php

INECC. (2009). Metales Pesados. Recuperado de http://www.inecc. gob.mx/sqre-temas/763-aqre-metales

Jaishankar, M., Tseten, T., Anbalagan, N., Mathew, B. B., \& Beeregowda, K. N.(2014). Toxicity, mechanism and health effects of some heavy metals. Interdisciplinary Toxicology, 7(2), 60-72. DOI:10.2478/intox-2014-0009

Jianlong, W. (2002). Biosorption of copper(II) by chemically modified biomass of Saccharomyces cerevisiae. Process Biochemistry, 37(8), 847-850. http://doi.org/10.1016/S0032-9592(01)00284-9

Jomova, K., Jenisova, Z., Feszterova, M., Baros, S., Liska, J., Hudecova, D., Rhodes, C. J., \& Valko, M. (2011). Arsenic: toxicity, oxidative stress and human disease. Journal of Applied Toxicology, 31(2), 95-107. DOI:10.1002/jat.1649

Kogej, A., \& Pavko, A. (2001). Comparison of Rhizopus nigricans in a pelleted growth form with some other types of waste microbial biomass as biosorbents for metal ions. World Journal of Microbiology and Biotechnology, 17(7), 677-685.

Kordialik-Bogacka, E. (2011). Surface properties of yeast cells during heavy metal biosorption. Central European Journal of Chemistry, 9(2), 348-351. http://doi.org/10.2478/s11532-011-0008-8

Kordialik-Bogacka,E.(2014). Saccharomyces pastorianus immobilized on brewer's spent grain in continuous system for lead ion biosorption. International Biodeterioration and Biodegradation, 96, 191-197. http://doi.org/10.1016/j.ibiod.2014.09.018

Kordialik-Bogacka, E., \& Diowksz, A. (2014). Metal uptake capacity of modified Saccharomyces pastorianus biomass from different types of solution. Environmental Science and Pollution Research, 21(3), 2223-2229. http://doi.org/10.1007/s11356-013-2144-5

Kulakovskaya, T., Ryazanova, L., Zvonarev, A., Khokhlova, G., Ostroumov, V., \& Vainshtein, M. (2018). The biosorption of cadmium and cobalt and iron ions by yeast Cryptococcus humicola at nitrogen starvation. Folia Microbiologica. 63(4), 507-510. DOI:10.1007/s12223-018-0583-6

Kuroda, K., \& Ueda, M. (2010). Engineering of microorganisms towards recovery of rare metal ions. Applied Microbiology and Biotechnology, 87(1), 53-60. http://doi.org/10.1007/s00253010-2581-8

Kwok, K. C. M., Koong, L. F., Al Ansari, T., \& McKay, G. (2018). Adsorption/desorption of arsenite and arsenate on chitosan and nanochitosan. Environmental Science and Pollution Research.25(15), 14734-14742. DOI:10.1007/s11356-0181501-9

Lata, S., Singh, P. K., \& Samadder, S. R. (2015). Regeneration of adsorbents and recovery of heavy metals: a review. International Journal of Environmental Science and Technology, 12(4), 14611478. DOI:10.1007/s13762-014-0714-9

Levenspiel, O. (1984). Flow in fluidized beds. En Engineering Flow and Heat Exchange. The Plenum Chemical Engineering Series. (pp. 135-147). Boston, MA, USA: Springer. https://doi. org/10.1007/978-1-4615-6907-7_7

Lin, J., \& Harichund, C. (2011). Industrial effluent treatments using heavy-metal removing bacterial bioflocculants. Water $S A, \mathbf{3 7 ( 2 ) ,}$ $265-270$.

López-Carrillo, L., Hernández-Ramírez, R. U., Gandolfi,A. J., OrnelasAguirre, J. M., Torres-Sánchez, L., \& Cebrian, M. E. (2014). Arsenic methylation capacity is associated with breast cancer in Northern Mexico. Toxicology and Applied Pharmacology, 280(1), 53-59. http://doi.org/10.1016/j.taap.2014.07.013

Machado, M. D., Janssens, S., Soares, H. M. V. M., \& Soares, E. V. (2009). Removal of heavy metals using a brewer's yeast strain of Saccharomyces cerevisiae: advantages of using dead biomass. Journal of Applied Microbiology, 106(6), 1792-1804. http://doi. org/10.1111/j.1365-2672.2009.04170.x

Machado, M. D., Soares, E. V., \& Soares, H. M. V. M. (2010). Removal of heavy metals using a brewer's yeast strain of Saccharomyces cerevisiae: chemical speciation as a tool in the prediction and improving of treatment efficiency of real electroplating effluents. Journal of Hazardous Materials, 180(1-3), 347-353. http://doi. 
org/10.1016/j.jhazmat.2010.04.037

Malgieri, G., Palmieri, M., Esposito, S., Maione, V., Russo, L., Baglivo, I., de Paola, I., Milardi, D., Diana, D., Zaccaro, L., Pedone, P. V., Fattorusso, R., \& Isernia, C. (2014). Zinc to cadmium replacement in the prokaryotic zinc-finger domain. Metallomics: Integrated Biometal Science, 6(1), 96-104.http://doi.org/10.1039/ c3mt00208j

Marques, P., Pinheiro, H. M., \& Rosa, M. F. (2007). Cd(II) removal from aqueous solution by immobilised waste brewery yeast in fixed-bed and airlift reactors. Desalination, 214, 343-351. http:// doi.org/10.1016/j.desal.2006.11.012

Mata, Y. N., Blázquez, M. L., Ballester, A., González, F., \& Muñoz, J. A. (2010). Studies on sorption, desorption, regeneration and reuse of sugar-beet pectin gels for heavy metal removal. Journal of Hazardous Materials, 178(1), 243-248. doi:https:// doi.org/10.1016/j.jhazmat.2010.01.069

Monachese, M. A. (2012). Sequesteration of lead, cadmium and arsenic by Lactobacillus species and detoxication potential. The University of Western Ontario.

Moreno-Rivas, S., Armenta-Corral, R., Frasquillo-Félix, M., LagardaDíaz, I., Vázquez-Moreno, L., \& Ramos-Clamont Montfort, G. (2016). Biosorción de cadmio en solución acuosa utilizando levadura de panadería (Saccharomyces cerevisiae). Revista Mexicana de Ingeniería Química, 15(3), 843-857.

Muter, O., Lubinya, I., Millers, D., Grigorjeva, L., Ventinya, E., \& Rapoport, A. (2002). Cr(VI) sorption by intact and dehydrated Candida utilis cells in the presence of other metals. Process Biochemistry, 38, 123-131.

Nagy, B., Tonk, S., Cerasella, I., Măicăneanu, A., \& Majdik, C. (2013). Biosorption of cadmium ions by unmodified, microwave and ultrasound modified brewery and pure strain yeast biomass. American Journal of Analytical Chemistry, 4, 63-71.

Naja, G. M., Murphy, V., Volesky, B. (2010) Biosorption, metals. En M. C. Flickinger. (Ed.), Encyclopedia of Industrial Biotechnology: Bioprocess, Bioseparation, and Cell Technology. (pp. 1-29). Hoboken, NJ, USA: Wiley. https://doi. org/10.1002/9780470054581.eib166

Niazi, N. K., Murtaza, B., Bibi, I., Shahid, M., White, J. C., Nawaz, M. F., Bashir, S., Shakoor, M. B., Choppala, G., Murtaza, G., \& Wang, H. (2016). Removal and recovery of metals by biosorbents and biochars derived from biowastes. En M. N. V. Prasad \& K. Shih (Eds.), Environmental Materials and Waste: Resource Recovery and Pollution Prevention. (pp. 149-177). Linn, MO, USA: Elsevier. https://doi.org/10.1016/B978-0-12-803837-6.00007-X

Özer, A., \& Özer, D. (2003). Comparative study of the biosorption of $\mathrm{Pb}(\mathrm{II}), \mathrm{Ni}(\mathrm{II})$ and $\mathrm{Cr}(\mathrm{VI})$ ions onto $S$. cerevisiae: determination of biosorption heats. Journal of Hazardous Materials, 100(1-3), 219-229. http://doi.org/10.1016/S0304-3894(03)00109-2

Pandey, P. K., Choubey, S., Verma, Y., Pandey, M., \& Chandrashekhar, K. (2009). Biosorptive removal of arsenic from drinking water. Bioresource technology, 100(2), 634-637.

Park, D., Yun, Y. S., \& Park, J. M. (2010). The past, present, and future trends of biosorption. Biotechnology and Bioprocess Engineering, 15(1), 86-102.
Pearson, R. G. (1963). Hard and soft acids bases. Journal of the American Chemical Society, 85(22), 3533-3539.

Pokethitiyook, P., \& Poolpak, T. (2016). Biosorption of heavy metal from aqueous solutions. In A. A. Ansari, S. S. Gill, R. Gill, G. R. Lanza, \& L. Newman (Eds.), Phytoremediation (pp. 113141). Switzerland: Springer International Publishing. http://doi. org/10.1007/978-3-319-40148-5

Purkayastha, D., Mishra, U., \& Biswas, S. (2014). A comprehensive review on $\mathrm{Cd}(\mathrm{II})$ removal from aqueous solution. Journal of Water Process Engineering, 2, 105-128. http://doi.org/10.1016/j. jwpe.2014.05.009

Rajendran, P., Muthukrishnan, J., \& Gunasekaran, P. (2003). Microbes in heavy metal remediation. Indian Journal of Experimental Biology, 41(9), 935-944.

Rajesh Kumar, S., Jayavignesh, V., Selvakumar, R., Swaminathan, K., \& Ponpandian, N. (2016). Facile synthesis of yeast crosslinked $\mathrm{Fe} 3 \mathrm{O} 4$ nanoadsorbents for efficient removal of aquatic environment contaminated with $\mathrm{As}(\mathrm{V})$. J Colloid Interface Sci, 484, 183-195. DOI:10.1016/j.jcis.2016.08.081

Rao, K., Mohapatra, M.,Anand, S., \& Venkateswarlu, P. (2010). Review on cadmium removal from aqueous solutions. International Journal of Engineering, Science and Technology, 2(7), 81-103. http://doi.org/10.4314/ijest.v2i7.63747

Rao, L. N., \& Prabhakar, G. (2011). Removal of heavy metals by biosorption - an overall review. Journal of Engineering Research and Studies, II(IV), 17-22.

Romera, E., Gonzalez, F., Ballester, A., Blazquez, M. L., \& Munoz, J. A. (2006). Biosorption with algae: a statistical review. Critical reviews in biotechnology, 26(4), 223-235.

Rosca, M., Hlihor, R. M., Cozma, P., Diana, E., Simion, I. M., \& Gavrilescu, M. (2015). Potential of biosorption and bioaccumulation processes for heavy metals removal in bioreactors. The 5th IEEE International Conference on E-Health and Bioengineering - EHB 2015 (pp. 1-4). IEEE.

Roy, D., Gaur, P., Verma, N., Pathireddy, M., \& Singh, K. P. (2013). Bioremediation of arsenic (III) from water using baker yeast Saccharomyces cerevisiae. International Journal of Environmental Bioremediation \& Biodegradation, 1(1), 14-19. http://doi. org/10.12691/ijebb-1-1-3

Safarik, I., Maderova, Z., Pospiskova, K., Baldikova, E., Horska, K., \& Safarikova, M. (2015). Magnetically responsive yeast cells: methods of preparation and applications. Yeast, 32(1), 227-237.

Salehizadeh, H., \& Shojaosadati, S. A. (2003). Removal of metal ions from aqueous solution by polysaccharide produced from Bacillus firmus. Water Research, 37(17), 4231-4235.

Say, R., Y1lmaz, N., \& Denizli, A. (2003). Biosorption of cadmium, lead, mercury, and arsenic ions by the fungus Penicillium purpurogenum. Separation Science and Technology, 38(9), 2039-2053.

Schwerdtle, T., Ebert, F., Thuy, C., Richter, C., Mullenders, L. H. F., \& Hartwig, A. (2010). Genotoxicity of Soluble and Particulate Cadmium Compounds: Impact on Oxidative DNA Damage and Nucleotide Excision Repair. Chemical Research in Toxicology, 23(2), 432-442. DOI:10.1021/tx900444w 
Selvakumar, R., Jothi, N. A., Jayavignesh, V., Karthikaiselvi, K., Antony, G. I., Sharmila, P. R., Kavitha, S., \& Swaminathan, K. (2011). As(V) removal using carbonized yeast cells containing silver nanoparticles. Water Research, 45(2), 583-592. http://doi. org/10.1016/j.watres.2010.09.034

Shankar, S., Shanker, U., \& Shikha. (2014). Arsenic contamination of groundwater: a review of sources, prevalence, health risks, and strategies for mitigation. The Scientific World Journal, 2014, 1-18. http://doi.org/10.1155/2014/304524

Shen, S., Li, X. F., Cullen, W. R., Weinfeld, M., \& Le, X. C. (2013). Arsenic binding to proteins. Chemical Reviews, 113(10), 77697792. http://doi.org/10.1021/cr300015c

Singh, S., Lee, W., DaSilva, N. A., Mulchandani, A., \& Chen, W. (2008). Enhanced arsenic accumulation by engineered yeast cells expressing Arabidopsis thaliana phytochelatin synthase. Biotechnology and Bioengineering, 99(2), 333-340.

Soares, E. V., \& Soares, H. M. V. M. (2012). Bioremediation of industrial effluents containing heavy metals using brewing cells of Saccharomyces cerevisiae as a green technology: A review. Environmental Science and Pollution Research, 19(4), 1066-1083. http://doi.org/10.1007/s11356-011-0671-5

Spence, C. L., \& Bailon, P. (2000). Fluidized-Bed Receptor-Affinity Chromatography. En P. Bailon, G. K. Ehrlich, W. J. Fung, W. Berthold (Eds.), Affinity Chromatography. Methods in Molecular Biology, Vol. 147 (pp. 25-39). Totowa, NJ, USA: Humana Press. https://doi.org/10.1007/978-1-60327-261-2 3

Tchounwou, P. B., Yedjou, C. G., Patlolla, A. K., \& Sutton, D. J. (2012). Heavy Metals Toxicity and the Environment. EXS, 101, 133-164. doi:10.1007/978-3-7643-8340-4_6

USEPA. (2016). Table of Regulated Drinking Water Contaminants. Recuperado de https:/www.epa.gov/your-drinking-water/tableregulated-drinking-water-contaminants

Vasudevan, P., Padmavathy, V., \& Dhingra, S. C. (2002). Biosorption of monovalent and divalent ions on baker's yeast. Bioresource Technology, 82(3), 285-289. http://doi.org/10.1016/S09608524(01)00181-X

Vasudevan, P., Padmavathy, V., \& Dhingra, S. C. (2003). Kinetics of biosorption of cadmium on baker's yeast. Bioresource Technology, 89(3), 281-287. http://doi.org/10.1016/S0960-8524(03)00067-1

Veglio, F., \& Beolchini, F. (1997). Removal of metals by biosorption : a review. Hydrometallurgy, 44, 301-316.

Vijayaraghavan, K., \& Balasubramanian, R. (2015). Is biosorption suitable for decontamination of metal-bearing wastewaters ? a critical review on the state-of-the-art of biosorption processes and future directions. Journal of Environmental Management, 160, 283-296. http://doi.org/10.1016/j.jenvman.2015.06.030

Vinopal, S., Ruml, T., \& Kotrba, P. (2007). Biosorption of $\mathrm{Cd}^{2+}$ and $\mathrm{Zn}^{2+}$ by cell surface-engineered Saccharomyces cerevisiae. International Biodeterioration and Biodegradation, 60(2), 96102. http://doi.org/10.1016/j.ibiod.2006.12.007

Wang, J., \& Chen, C. (2006). Biosorption of heavy metals by Saccharomyces cerevisiae: a review. Biotechnology Advances,
24(5), 427-451.http://doi.org/10.1016/j.biotechadv.2006.03.001

Wang, J., \& Chen, C. (2009). Biosorbents for heavy metals removal and their future. Biotechnology Advances, 27(2), 195-226. http:// doi.org/10.1016/j.biotechadv.2008.11.002

Wang, S., \& Zhao, X. (2009). On the potential of biological treatment for arsenic contaminated soils and groundwater. Journal of environmental Management, 90(8), 2367-2376.

WHO. (2011). Cadmium in drinking water. Background Document for Preparation of WHO Guidelines for Drinking-water Quality. Geneva, Switzerland. Recuperado de http://www.who.int/ water_sanitation_health/dwq/chemicals/cadmium.pdf

WHO.(2006). Guidelines for drinking-water quality. Recommendations (Vol. 1). Geneva, Switzerland. Recuperado de http://www.who. int/water_sanitation_health/dwq/gdwqvol32ed.pdf

Wu, Y., Wen, Y., Zhou, J., Dai, Q., \& Wu, Y. (2012). The characteristics of waste Saccharomyces cerevisiae biosorption of arsenic (III). Environmental Science and Pollution Research, 19(8), 3371-3379.

Wykoff, D. D., \& Shea, E. K. O. (2001). Phosphate transport and sensing in Saccharomyces cerevisiae. Genetics, 159(4), 1491-1499.

Wysocki, R., Chéry, C. C., Wawrzycka, D., Van Hulle, M., Cornelis, R., Thevelein, J. M., \& Tamás, M. J. (2001). The glycerol channel Fps1p mediates the uptake of arsenite and antimonite in Saccharomyces cerevisiae. Molecular Microbiology, 40(6), 1391-1401.

Yadanaparthi, S. K. R., Graybill, D., \& von Wandruszka, R. (2009). Adsorbents for the removal of arsenic, cadmium, and lead from contaminated waters. Journal of Hazardous Materials, 171(1-3), 1-15. https://doi.org/10.1016/j.jhazmat.2009.05.103

Yin, Y., Wang, J., Yang, X., \& Li, W. (2016). Removal of strontium ions by immobilized Saccharomyces cerevisiae in magnetic chitosan microspheres. Nuclear Engineering and Technology. 49(1), 172177. http://doi.org/10.1016/j.net.2016.09.002

Zeraatkar, A. K., Ahmadzadeh, H., Talebi, A. F., Moheimani, N.R., McHenry, M. P. (2016). Potential use of algae for heavy metal bioremediation, a critical review. Journal of Environmental Management, 181, 817-831. https://doi.org/10.1016/j. jenvman.2016.06.059

Zhang, Y., Liu, W., Zhang, L., Wang, M., \& Zhao, M. (2011). Application of bifunctional Saccharomyces cerevisiae to remove lead(II) and cadmium(II) in aqueous solution. Applied Surface Science, 257(23), 9809-9816. http://doi.org/10.1016/j. apsusc.2011.06.026

Ziagova, M., Dimitriadis, G., Aslanidou, D., Papaioannou, X., Tzannetaki, E. L., \& Liakopoulou-Kyriakides, M. (2007). Comparative study of $\mathrm{Cd}$ (II) and $\mathrm{Cr}$ (VI) biosorption on Staphylococcus xylosus and Pseudomonas sp. in single and binary mixtures. Bioresource technology, 98(15), 2859-2865.

Zoghi, A., Khosravi-Darani, K., \& Sohrabvandi, S. (2014). Surface binding of toxins and heavy metals by probiotics. Mini-Reviews in Medicinal Chemistry, 14(1), 84-98. http://doi.org/10.2174/13 89557513666131211105554 